\title{
Transcriptome analysis of the differential effect of the NADPH oxidase gene RbohB in Phaseolus vulgaris roots following Rhizobium tropici and Rhizophagus irregularis inoculation
}

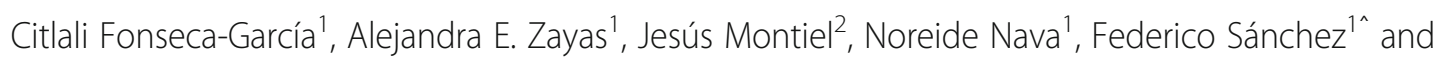
Carmen Quinto ${ }^{1 *}$

\begin{abstract}
Background: Reactive oxygen species (ROS) are generated by NADPH oxidases known as respiratory burst oxidase homologs (RBOHs) in plants. ROS regulate various cellular processes, including the mutualistic interactions between legumes and nitrogen-fixing bacteria or arbuscular mycorrhizal (AM) fungi. Rboh is a multigene family comprising nine members (RbohA-l) in common bean (Phaseolus vulgaris). The RNA interference-mediated silencing of RbohB (PvRbohB-RNAi) in this species diminished its ROS production and greatly impaired nodulation. By contrast, the PvRbohB-RNAi transgenic roots showed early hyphal root colonization with enlarged fungal hypopodia; therefore, we proposed that PvRbohB positively regulates rhizobial infection (Rhizobium tropici) and inhibits AM colonization by Rhizophagus irregularis in P. vulgaris.
\end{abstract}

Results: To corroborate this hypothesis, an RNA-Seq transcriptomic analysis was performed to identify the differentially expressed genes in the PVRbohB-RNAi roots inoculated with Rhizobium tropici or Rhizophagus irregularis. We found that, in the early stages, root nodule symbioses generated larger changes of the transcriptome than did AM symbioses in P. vulgaris. Genes related to ROS homeostasis and cell wall flexibility were markedly upregulated in the early stages of rhizobial colonization, but not during AM colonization. Compared with AM colonization, the rhizobia induced the expression of a greater number of genes encoding enzymes involved in the metabolism of auxins, cytokinins, and ethylene, which were typically repressed in the PvRbohB-RNAi roots.

Conclusions: Our research provides substantial insights into the genetic interaction networks in the early stages of rhizobia and AM symbioses with P. vulgaris, as well as the differential roles that RbohB plays in processes related to ROS scavenging, cell wall remodeling, and phytohormone homeostasis during nodulation and mycorrhization in this legume.

Keywords: Transcriptome, Phaseolus vulgaris, Rboh, Nodulation, Mycorrhization, Symbiosis

\footnotetext{
* Correspondence: quinto@ibt.unam.mx

1Departamento de Biología Molecular de Plantas, Instituto de Biotecnología,

Universidad Nacional Autónoma de México, Avenida Universidad 2001,

Colonia Chamilpa, Cuernavaca, Morelos 62210, Mexico

Full list of author information is available at the end of the article
}

(c) The Author(s). 2019 Open Access This article is distributed under the terms of the Creative Commons Attribution 4.0 International License (http://creativecommons.org/licenses/by/4.0/), which permits unrestricted use, distribution, and reproduction in any medium, provided you give appropriate credit to the original author(s) and the source, provide a link to the Creative Commons license, and indicate if changes were made. The Creative Commons Public Domain Dedication waiver (http://creativecommons.org/publicdomain/zero/1.0/) applies to the data made available in this article, unless otherwise stated. 


\section{Background}

Phosphorus and nitrogen are essential elements, the deficiency of which restricts plant growth. The acquisition of these nutrients can be facilitated through symbiotic associations between leguminous roots and soil microorganisms [1]. Arbuscular mycorrhizal (AM) fungi associate with plant roots and mobilize phosphate and nitrogen from the soil to the plant partner. In legumes, gram-negative soil bacteria called rhizobia induce the formation of root nodules, specialized organs in which atmospheric dinitrogen is fixed by the bacterial microsymbiont into a form usable by plants [2]

In plant-AM associations, strigolactones exuded by the plant roots promote hyphal branching and the biosynthesis of lipochito-oligosaccharides called $M y c$ factors [3], which induce several physiological and molecular responses in the plant partner. The mutual recognition of both the macro- and micro-symbionts leads to the plantorchestrated formation of the fungal hypopodium on the surface of the root epidermis and the prepenetration apparatus in the underlying epidermal cell, which forms the entry route of the microsymbiont. At this stage, the hyphae grow and ramify both intra- and intercellularly in the root, entering the inner cortical cells to form branched structures called arbuscules. These arbuscules are surrounded by a plant-derived membrane, named the periarbuscular membrane, through which nutrients are exchanged between the fungus and the plant host [4].

The legume-rhizobia symbiosis is also initiated by a molecular dialogue between symbionts. The flavonoids secreted into the rhizosphere by the legume roots are perceived by the rhizobial bacteria, which respond by biosynthesizing and secreting lipochito-oligosaccharides known as Nod factors into the rhizosphere. These molecules are specifically recognized by the plant root hair cell receptors and induce several physiological, cellular, and molecular responses. First, the bacteria attach to the root hair tips, prompting the swelling and curling that entraps the microsymbiont within a so-called infection chamber. At this point, a tubular structure known as the infection thread (IT) is formed in the infection chamber, allowing the bacteria to enter the root hair cells. The IT migrates to the inner layers of the root cortex, which reestablish their mitotic activity to form the nodule primordium, the precursor of the nitrogen-fixing nodule. Finally, the bacteria are released from the IT into specific cells of the inner cortex, where they become bacteroids that transform atmospheric dinitrogen into ammonia, a source of nitrogen that is assimilable by the plant [5].

Both mutualistic associations originate in the rhizosphere, and although obvious differences exist between these two processes, several molecular signals are recruited by the plant cell for both symbioses. Cell imaging experiments using a calcium chameleon reporter revealed that rhizobial and AM symbionts both trigger calcium spiking in the root cells of Medicago truncatula, which is likely required for the formation of the pre-IT and the prepenetration apparatus, respectively [6]. The activation of calcium spiking in the epidermal cells requires the enzyme 3-HYDROXY-3-METHYLGLUTARYL CoA REDUCTASE1, a key regulator of the mevalonate pathway reported to interact with the plasma membrane receptor-like kinase SYMBIOSIS RECEPTOR KINASE/ DOES NOT MAKE INFECTIONS2 (SYMRK/DMI2) [79]. Downstream, the calcium oscillations are decoded by a nuclear $\mathrm{Ca}^{2+} /$ calmodulin-dependent protein kinase and its interaction partner, CYCLOPS [10, 11]. Nucleoporins and cationic channels located in the nuclear envelope are also part of the common symbiotic pathways [12]. Silencing or mutating these shared genes affects the initial stages of both AM and rhizobial symbioses.

Despite these similarities, reactive oxygen species (ROS) produced by NADPH oxidases in legumes, known as respiratory burst oxidase homologs ( $\mathrm{RBOHs})$, seem to play contrasting roles in these mutualistic relationships. In rhizobial symbiosis, the $\mathrm{RBOHs}$ promote nodulation; for example, silencing $R b o h B$ expression impairs IT progression and nodule development in Phaseolus vulgaris roots inoculated with Rhizobium tropici, while its overexpression enhances rhizobial infection [13, 14]. An analogous phenotypic effect was observed in $M$. truncatula root hairs inoculated with Sinorhizobium meliloti when MtROP9 (encoding RHO-LIKE PROTEIN9, a Rho-like GTPase believed to positively regulate the RBOHs) was silenced [15]. Other stages of the nodulation process are also positively regulated by legume NADPH oxidases [16]; for instance, the downregulation of $M t R b o h A$ and $P v R b o h B$ expression significantly reduced nitrogen fixation in $M$. truncatula and $P$. vulgaris nodules, respectively [13, 17]. In AM symbiosis, however, mounting evidence suggests that $\mathrm{RBOH}$-dependent ROS production must be switched off to facilitate the colonization process. Hyphal colonization is promoted in transgenic MtROP9-silenced roots [15], while the loss of function of $P v R b o h B$ enhances the size of the fungal hypopodium and promotes hyphal colonization in $P$. vulgaris composite plants [18]. The opposite effect was observed in $P$. vulgaris roots overexpressing $P v R b o h B$, in which AM invasion was substantially reduced [14]. The RbohE promoter is active in the arbuscule-hosting cells of M. truncatula, while its silencing through RNA interference (RNAi) impairs arbuscule formation with multiple cell penetration attempts [19]. These reports further demonstrate the crucial and contrasting roles of $\mathrm{RBOH}$-dependent ROS production in these mutualistic associations; however, recent work suggests that the role of RBOHs in legume-AM symbioses is more complex.

Studies of $P v R b o h B$-silenced or $P v R b o h B$-overexpressing transgenic bean roots revealed contrasting effects during 
the early stages of AM and rhizobial symbiotic processes in P. vulgaris $[13,14,18]$, leading us to propose that $\mathrm{RBOH}-$ produced ROS perform differential functions during the initial stages of these two symbiotic processes. Here, we performed a transcriptomic analysis of $P$. vulgaris using RNA-Seq, with the aim of identifying genes that are differentially expressed between control and $P v R b o h B$-silenced transgenic $P$. vulgaris roots inoculated with either $R$. tropici or Rhizophagus irregularis. This study unveils the transcriptomic profile of several biological processes in response to rhizobia inoculation, which is absent or only partially activated in the $\mathrm{AM}$-inoculated roots.

\section{Results}

Transcriptomic sequencing of rhizobia and AM symbioses in $P$. vulgaris

Previous studies conducted in our laboratory showed that PvRbohB plays crucial and putatively contrasting roles in rhizobial and AM symbioses in P. vulgaris roots. Furthermore, under nonsymbiotic conditions, the lateral root densities of the transgenic PvRbohB-silenced (PvRbohBRNAi) plants were shown to be reduced relative to the control, indicating that $P v R b o h B$ participates in P. vulgaris root development $[13,18]$. To further explore the impact of $P v R b o h B$ silencing on $P$. vulgaris gene expression, the transcriptomes of the control (nonsilenced transgenic roots) and PvRbohB-RNAi roots inoculated with rhizobia (R. tropici) or AM fungi ( $R$. irregularis) were analyzed using RNA-Seq. In each biological condition, more than 34 million reads were obtained. The read lengths were 75 to $101 \mathrm{bp}$, with an average quality score of 28 to 35 (Additional file 1: Table S1). Mapping the reads to the P. vulgaris reference genome revealed a 95 to $98 \%$ coverage of the approximately 23,000 unigenes for each condition (Additional file 2: Table S2). The data were deposited in the NCBI databases under the BioProject accession number PRJNA482464.

In order to evaluate the variability between biological replicates, we performed ordination analyses for control and PvRbohB-RNAi samples. The multidimensional scaling (MDS) analyses showed that the data sets displayed separated clustering by the control and PvRbohB-RNAi samples without inoculation and inoculated with rhizobia (Additional file 4: Figure S1). However, the clustering of the AM data showed that replica number three of the controls (Ctrl_Myc_3) and PvRbohB-RNAi (Bi_Myc_3) were outside of the ordering. This result was corroborated by a correlation analysis, where Pearson's correlation coefficients between replicas were low when replicate number three was analyzed (Additional file 4: Figure S1). Although Pearson's correlation coefficients of some uninoculated and rhizobia inoculated samples were not relatively high, the clustering was ordinated separately between the both mentioned conditions.
Considering this variability of the AM data, we decided to delete the replica number three of the controls and $P v R b o h B$-RNAi for further analysis.

\section{Comparative analysis of the transcriptomic profiles of rhizobia and $A M$ symbioses in $P$. vulgaris at 7 days postinoculation}

Over the past decade, a compendium of transcriptomic resources has been developed for several legumes in rhizobial and AM symbioses [20-27]; nevertheless, the early stages of rhizobia- and AM-inoculated roots have rarely been explored and compared. Here, we found that, at 7 days postinoculation (dpi), 2741 genes were differentially expressed in roots inoculated with rhizobia relative to the uninoculated control (Figs. 1 and 2), using a cutoff threshold of $\geq 1.5 \log 2$ FoldChange and a FDR-adjusted $P$-value of $\leq 0.05$. However, only 540 genes were differentially expressed between AM- and uninoculated roots (Figs. 1 and 2). The proportion of upregulated and downregulated genes was similar in rhizobial- and AM-inoculated P. vulgaris roots (Fig. 2a), though only 152 genes were shared (Fig. 2b). A total of 1402 and 278 were upregulated differentially expressed genes (DEGs) in the rhizobial and AM roots, respectively, of which 52 upregulated DEGs were shared between both datasets (Fig. 2c). The rhizobiainoculated roots had 1339 downregulated genes, while the AM roots had only 262 downregulated genes, 84 of which were shared between both biological treatments (Fig. 2d). Only 16 genes were found to be differentially regulated in the two symbioses; two were upregulated during nodulation and downregulated in mycorrhization, while 14 genes were downregulated in nodulation and upregulated during mycorrhization (Fig. 2e). These results suggest that these genes could play important differential roles in the early stages of nodulation and mycorrhization; however, further functional analyses are required to test this hypothesis.

The DEGs were annotated functionally within three Gene Ontology (GO) categories: biological process (BP), molecular function (MF), and cellular component (CC) (Additional file 5: Figure S2). There were clear differences in upregulated and downregulated genes between nodulation and mycorrhization conditions in BP. Amongst the upregulated genes, the response to stress, biosynthetic process, small molecule metabolic process, and cellular protein modification process constitute approximately $60 \%$ of the GO terms for nodulation condition. These same categories were less represented in the upregulated GO terms under mycorrhization conditions; catabolic process and cellular nitrogen compound metabolic process constituted around $40 \%$ of the GO terms under mycorrhization. Regarding the MF category, ion binding was the most abundant group in both biological treatments. Particularly in mycorrhized roots, the GO terms of up- and downregulated genes presented a similar composition, with a slight induction of genes related 


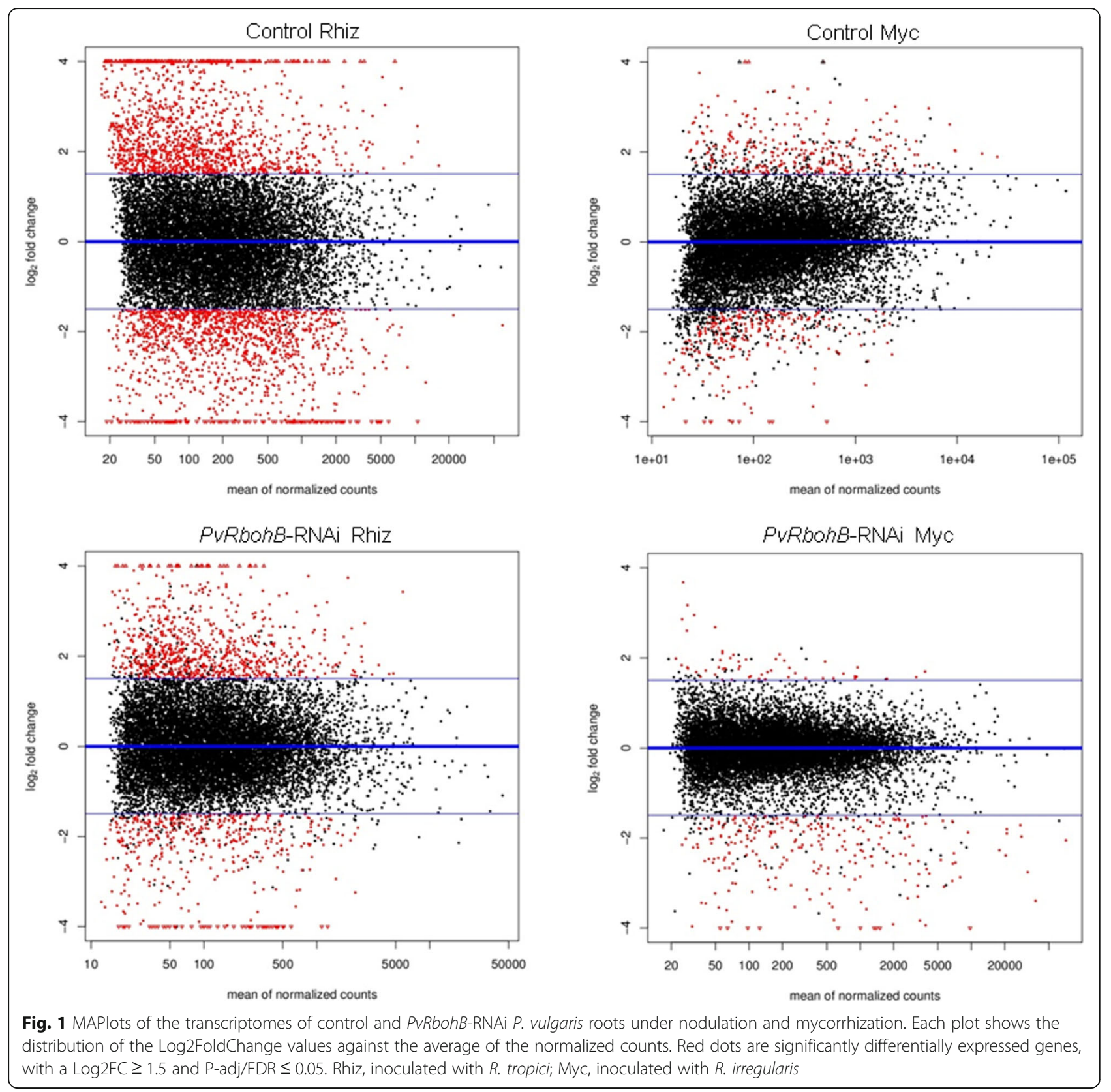

to kinase activity. However, in nodulated roots, several functional categories were downregulated, highlighting ion binding and oxidoreductase activity. In the CC category, both the up- and downregulated genes under mycorrhization conditions constituted three main groups: nucleus, endoplasmic reticulum, and plasma membrane. By contrast, under nodulation conditions, up- and downregulated genes had different functional groups, sharing only protein containing complex. Thus, GO term analysis revealed that the vast genetic reprograming observed in the early stages of nodulation and the more moderate changes observed during early mycorrhization largely involved genes associated with biological processes and cellular components (Additional file 5: Figure S2).

Effect of PvRbohB silencing on the rhizobia transcriptome and AM symbioses in $P$. vulgaris at early stages of colonization

$P v R b o h B$ silencing is known to affect the expression of several genes involved in nodulation and mycorrhization in $P$. vulgaris $[13,18]$; however, this gene is also expressed in several organs under nonsymbiotic conditions, and its silencing negatively affects the development of the lateral roots [28]. In this study, we found 

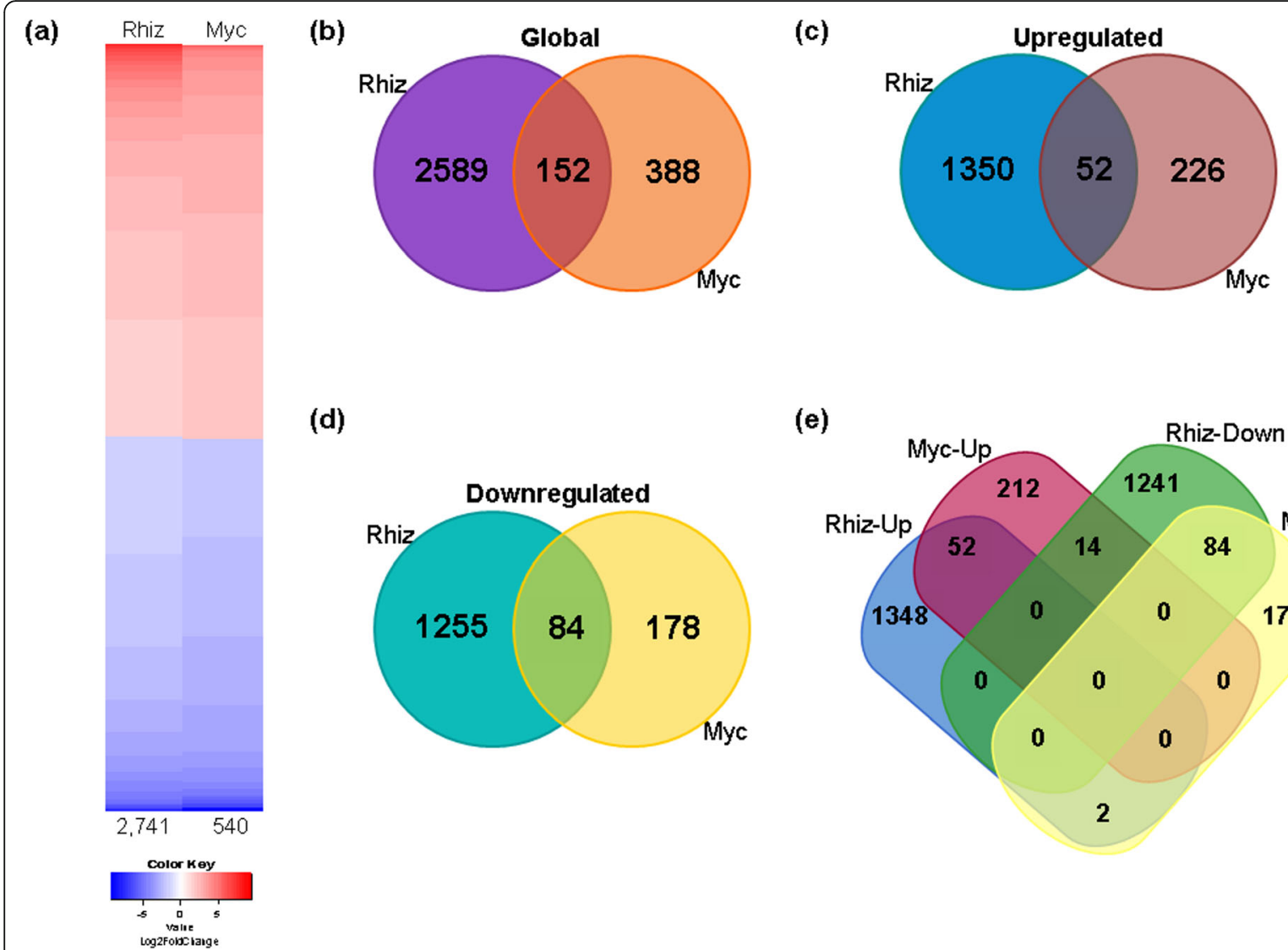

(e)

Fig. 2 Global analysis of DEGs in rhizobia-inoculated and mycorrhized roots of P. vulgaris. a Heatmap of the total number of DEGs in roots at 7 dpi with R. tropici (Rhiz) or R. irregularis (Myc) relative to the noninoculated roots. b-e Venn diagrams indicate the total number of DEGs (b), and the numbers of upregulated (Up) (c), downregulated (Down) (d), and overlapping (e) genes in the rhizobia-inoculated and mycorrhizal roots. The DEGs were identified using a cutoff threshold of Log2FC $\geq 1.5$ and a P-adj/FDR $\leq 0.05$ in the DESeq, EdgeR, and NOISeq packages of Bioconductor $\mathrm{R}$

that $P v R b o h B$ silencing causes differential expression of 757 genes in noninoculated $P$. vulgaris roots, of which 234 were upregulated and 523 were downregulated (Fig. 3a). This result shows that $P v R b o h B$ upregulates a greater number of genes than it downregulates. Several peroxidases and ethylene-related genes were induced in the $P v R b o h B$-RNAi roots, suggesting a possible increase in the ROS and ethylene levels of these plants. ROS, which are known to be involved in a variety of processes in plants, could potentially be upregulated by ethylene [29]. PvRbohB silencing repressed the expression of genes involved in cell wall remodeling, such as CELLULOSE SYNTHASE and XYLOGLUCAN ENDOTRANSGLUCOSYLASE/HYDROLASE, together with important genes in the cell cycle and auxin biosynthesis, such as the gene encoding THE INDOLE-3-PYRUVATE MONOOXYGENASE YUCCA5 (Fig. 3b). Furthermore, a global functional annotation of the DEGs using GO terms indicated an induction in the expression of genes involved in biological regulation and catabolic processes, those with transferase and transmembrane transferase activities, as well as those involved in extracellular processes (Additional file 6: Figure S3). By contrast, the silencing of $P v R b o h B$ repressed the expression of genes related to signal transduction, cellular nitrogen compound metabolic processes, and kinase activity (Additional file 6: Figure S3), suggesting that $P v R b o h B$ plays a role in the signaling and gene regulation processes of $P$. vulgaris.

The inoculation of PvRbohB-RNAi roots with $R$. tropici or $R$. irregularis affected the expression of 1328 and 302 genes, respectively (Fig. 4a-b). In response to rhizobial inoculation, 1402 genes were upregulated in the control roots; however, only 293 of these genes were also induced in the inoculated PvRbohB-RNAi roots (Fig. 4c, e). Similarly, in mycorrhized roots, of the 278 genes upregulated in the control transgenic roots, only two were induced in PvRbohB-RNAi roots (Fig. 4c, f). Furthermore, 42 of the genes upregulated during mycorrhization in the control roots were downregulated in the PvRbohB-RNAi roots (Fig. 4f). 


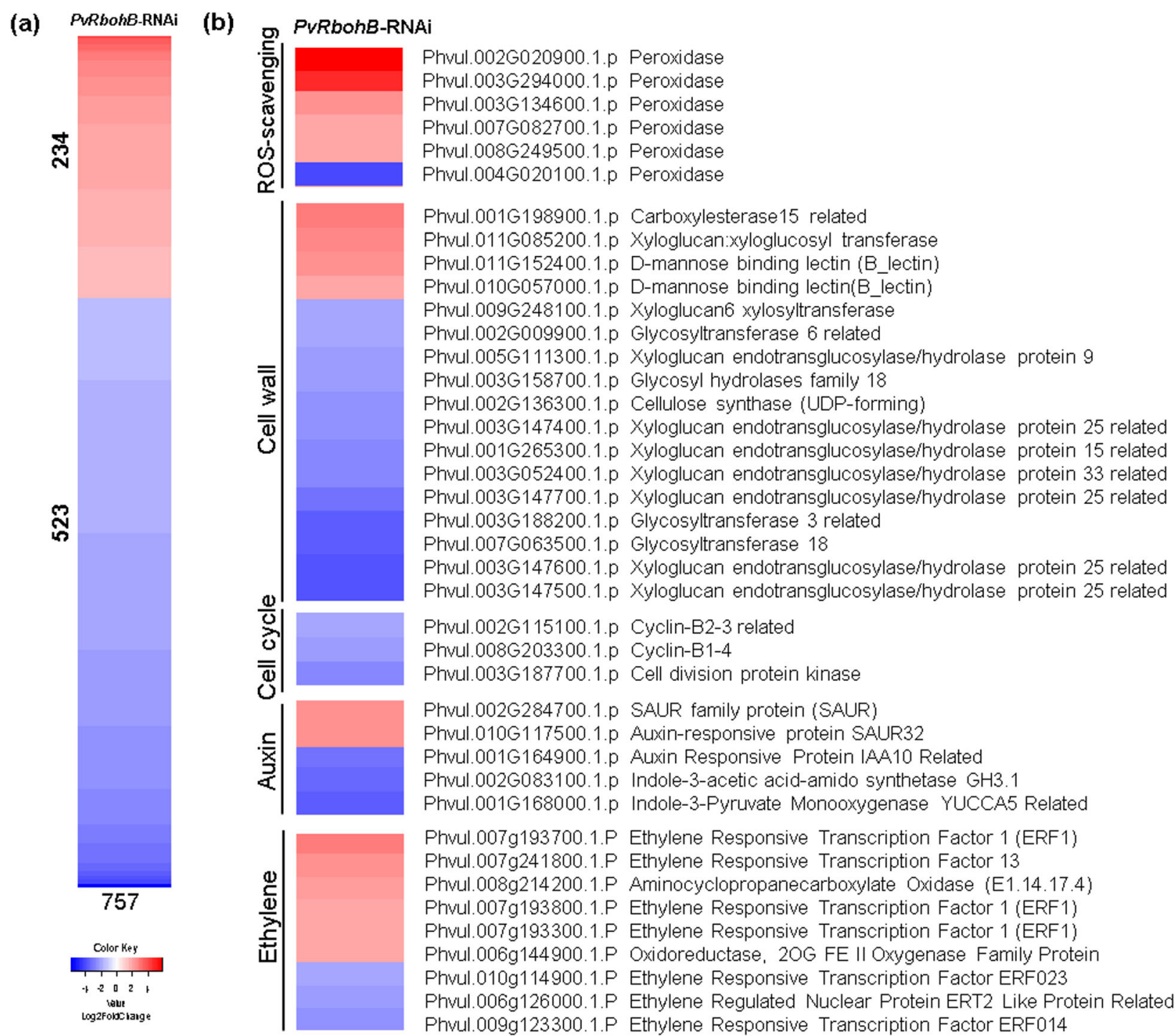

Fig. 3 Global analysis of the DEGs in PVRbohB-RNAi P. vulgaris roots under nonsymbiotic conditions. a Heatmap of all DEGs. b Heatmap analyses of ROS-scavenging, cell wall, and cell cycle genes. The color bars represent the Log2FoldChange of the DEGs, with red and blue representing the upregulated and downregulated genes, respectively. A cutoff threshold of $\log 2 F C \geq 1.5$ and P-adj/FDR $\leq 0.05$ was used

The normal transcriptional repression of a large set of genes during both symbiotic processes was substantially altered in the PvRbohB-RNAi roots. Approximately $85 \%$ of the downregulated genes in the rhizobial-inoculated control roots were not downregulated in the PvRbohBsilenced roots at $7 \mathrm{dpi}$ (Fig. 4d, e). Furthermore, only $2 \%$ of the 262 downregulated genes in the mycorrhized control roots were similarly downregulated in the $P v R b o h B$ RNAi roots, while an additional 201 genes were downregulated in these transgenic plants, suggesting that the early stages of AM symbiosis were strongly impacted by $P v R b o h B$ silencing. Under nodulation conditions, 57 of the upregulated genes in the $P v R b o h B$-RNAi roots were downregulated in the control roots. Moreover, the functional annotation of these genes indicated that the main changes caused by the silencing of $P v R b o h B$ at the functional level were also observed in $P$. vulgaris under nodulation conditions, while there were specific modifications to catabolic processes, signal transduction, transmembrane transporter activity, and plasma membrane at 7 dpi with AM (Additional file 7: Figure S4). These results could be related to the early stages of colonization by both microsymbionts.

To assess the efficacy and specificity of the $\operatorname{Rboh} B$ gene silencing, we quantified $P v R b o h B$ expression using both RNA-Seq and reverse-transcription quantitative PCR (RT-qPCR) data (Additional file 8: Figure S5). The PvRbohB-RNAi roots were found to have an $80 \%$ reduction in the transcript level of this gene relative to the control, supporting the resulting phenotype. Therefore, 
(a)

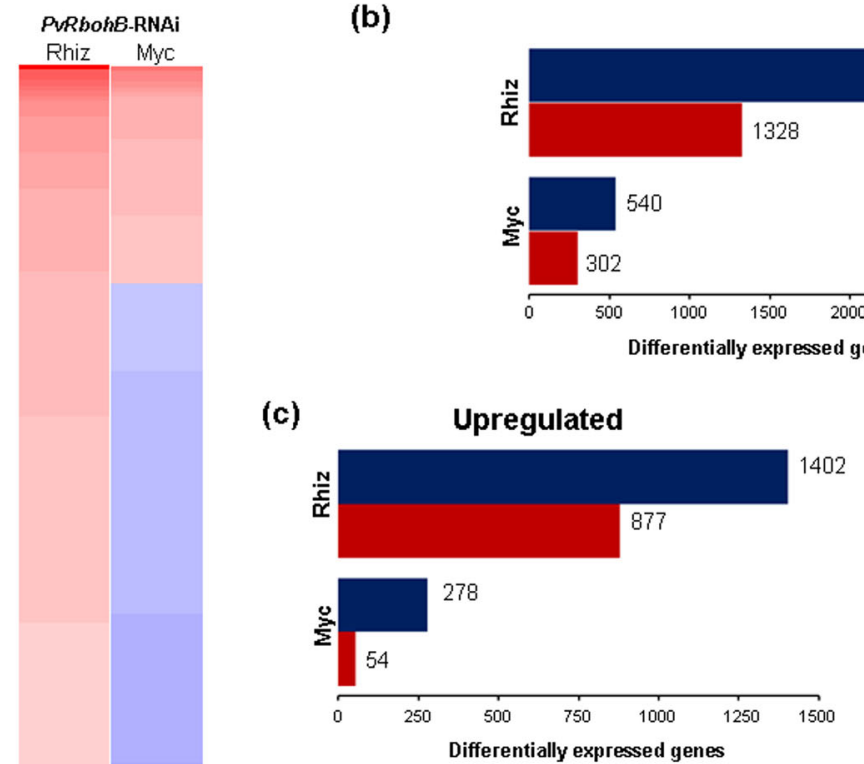

(e)
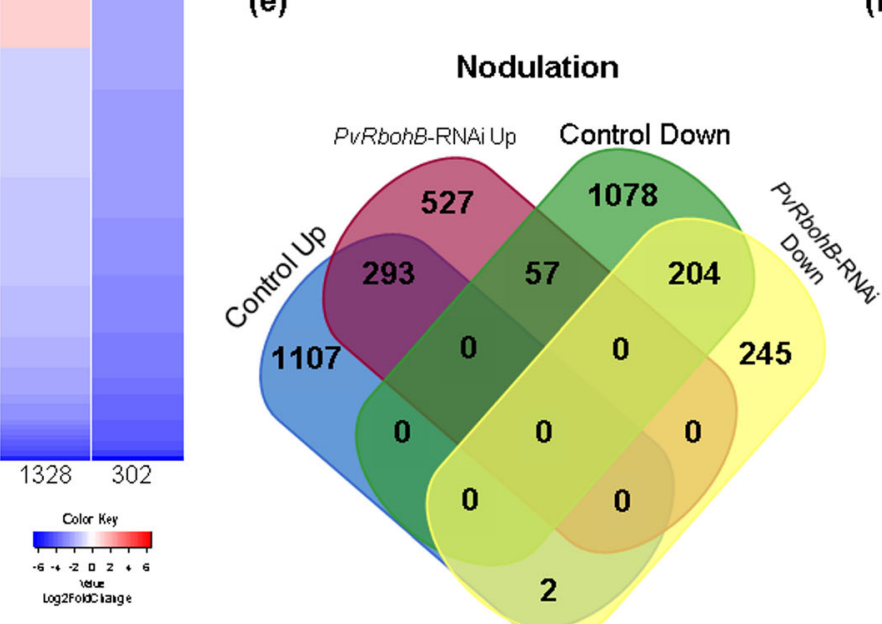

(d)

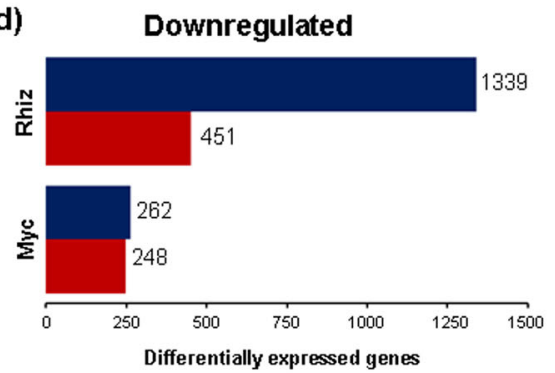

(f)

(f)

Mycorrhization

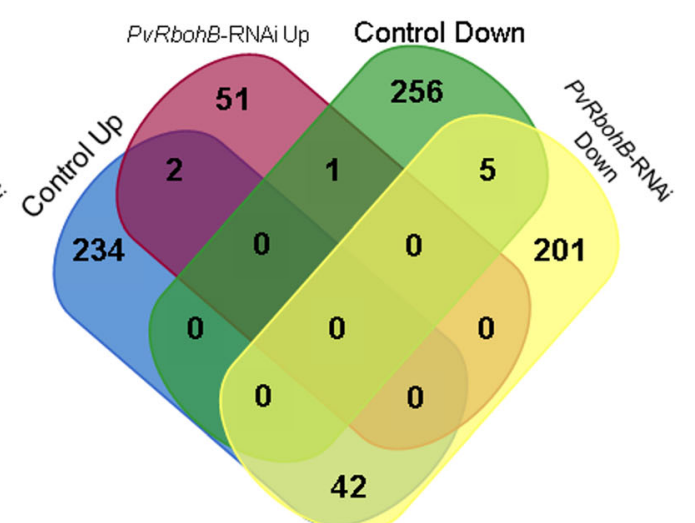

- Control

- PVRbohB-RNAi

Fig. 4 Global analysis of the DEGs in rhizobia-inoculated and mycorrhized PvRbohB-RNAi roots. a Heatmap of all DEGs between PvRbohB-RNAi roots inoculated with $R$. tropici (Rhiz) or $R$. irregularis (Myc) compared to the noninoculated PvRbohB-RNAi roots. Number of total DEGs (b), upregulated DEGs (Up) (c), and downregulated DEGs (Down) (d) identified between the control and PVRbohB-RNAi roots under nodulation and mycorrhization conditions. Venn diagrams show the intersections between the upregulated and downregulated DEGs shared between the nodulation (e) and mycorrhization (f) processes in control and silenced roots. A cutoff threshold of Log2FC $\geq 1.5$ and P-adj/FDR $\leq 0.05$ was used

the RT-qPCR results support the findings obtained in the RNA-Seq analysis.

Regulation of ROS- and cell wall-related genes in PvRbohB-RNAi roots under symbiotic conditions

As previously mentioned, $P v R b o h B$ silencing negatively impacts nodulation and positively affects mycorrhization in $P$. vulgaris. We evaluated the effect of $P v R b o h B-R N A i$ on the expression of the ROS-scavenging genes, since $\mathrm{RBOHs}$ are prominent ROS-generating systems in plants [30]. In this study, we found that the expression levels of 28 ROSscavenging genes were increased in the control roots inoculated with rhizobia, most of which encoded class-III peroxidases (Fig. 5a). In the PvRbohB-silenced roots, however, only 12 peroxidase genes were upregulated. In mycorrhized control roots, only five ROS-scavenging peroxidase genes were upregulated and three were downregulated; however, the expression levels of these genes were unaffected in the PvRbohB-RNAi roots (Fig. 5a).

ROS metabolism is tightly linked to cell wall remodeling. Hydroxyl radicals are involved in the loosening of cell walls via an apoplastic peroxidase-dependent mechanism, and hydrogen peroxide is involved in cell wall lignification $[31,32]$. The cell wall must be dynamically 
(a)
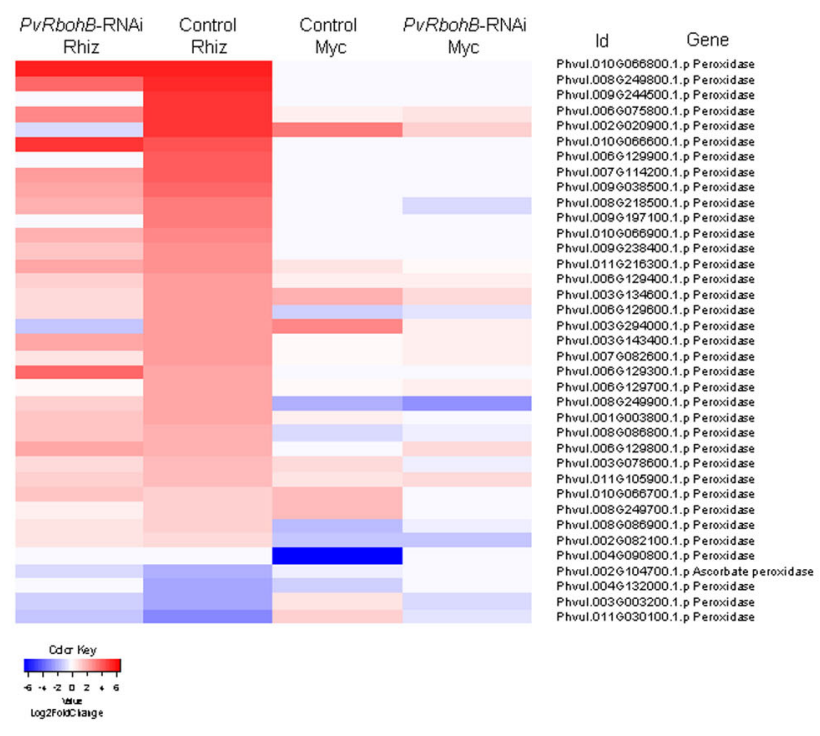

(b)
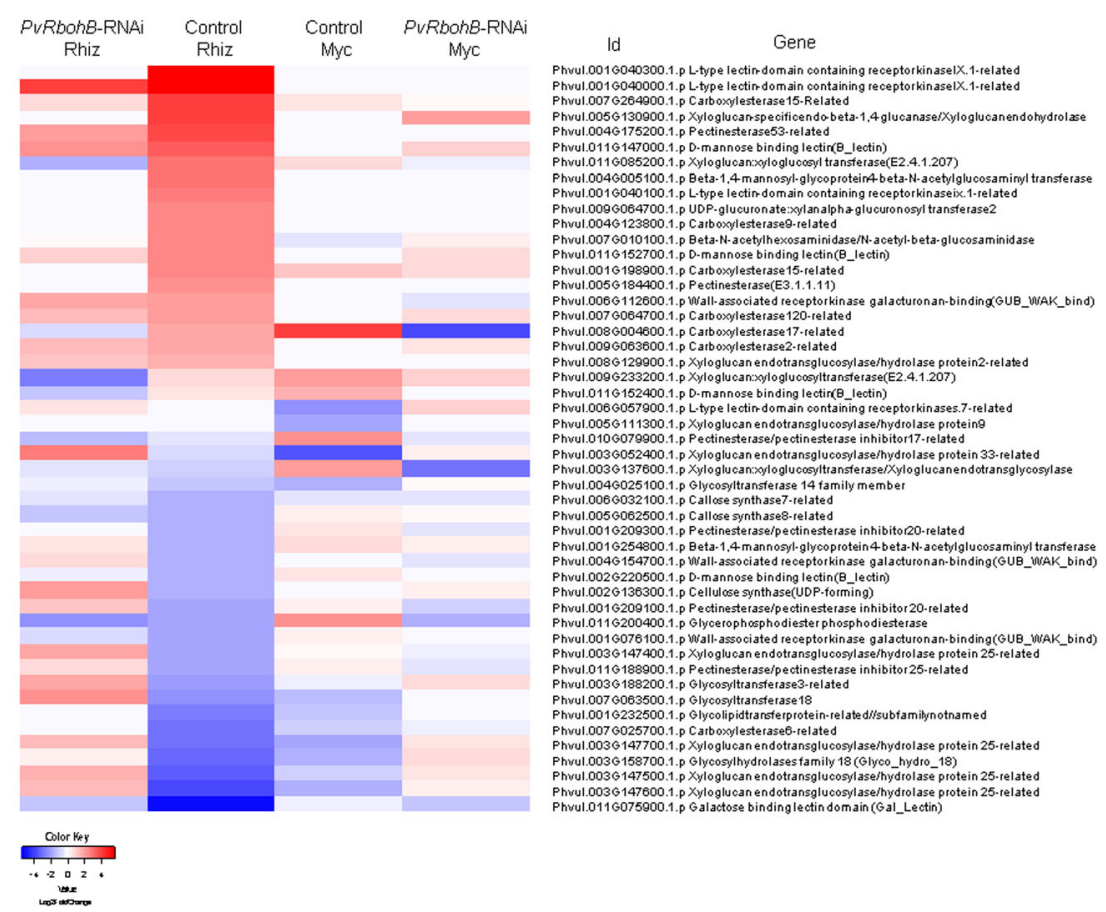

Fig. 5 Heatmap of the expression patterns of genes related to ROS scavenging and cell wall biosynthesis. DEGs encoding proteins related to ROS metabolism (a) and cell wall biosynthesis (b) in the control and PVRbohB-RNAi P. vulgaris roots, at 7 dpi with rhizobia or AM. The color bars represent the Log2FoldChange of the DEGs, with red and blue representing the upregulated and downregulated genes, respectively. A cutoff threshold of $\log 2 \mathrm{FC} \geq 1.5$ and $\mathrm{P}$-adj/FDR $\leq 0.05$ was used

modulated to allow for the successful invasion of rhizobia and AM [33]. Here, we identified DEGs related to plant cell wall biogenesis, such as those encoding BETA-1, 4-GLUCANASES, PECTINESTERASE, LECTINS, CARBOXYLESTERASE, and UDP-GLUCURONATE:XYLANALPHA GLUCURONOSYLTRANSFERASE, between the inoculated and noninoculated plants. Rhizobial inoculation induced the differential expression of more genes than did AM colonization (Fig. 5b), reflecting the differences in the developmental programs and kinetics of these symbioses. Under nodulation conditions, genes involved in cell wall biogenesis were induced in the PvRbohB-RNAi roots; however, some of these were downregulated in the control roots. Similarly, PvRbohB silencing had a clear influence on cell wall biosynthesis genes during mycorrhization, as only those encoding XYLOGLUCAN: 
XYLOGLUCOSYLTRANSFERASE and CARBOXYLESTERASE shared the same expression profile as the mycorrhized control roots (Fig. 5b). These results confirm the role of $R b o h B$ in growth and development processes in P. vulgaris.

\section{Signaling of phytohormone-related genes during rhizobial and AM symbioses}

Numerous reports have demonstrated a close relationship between ROS and several phytohormones during plant development and responses to stresses [34]. The production of ROS by AtRBOHD is an important signal for auxinregulated cell division during lateral root formation in Arabidopsis thaliana [35]. We identified 15 upregulated and 6 downregulated auxin-related genes in the rhizobiainoculated control roots, which were mainly early auxin response and regulatory genes (Fig. 6a). The five upregulated early auxin signaling genes in the mycorrhized control roots differed from the auxin-induced genes in the nodulated control roots, indicating a differential regulation of the auxin-related genes in these symbiotic processes (Fig. 6a). These results were confirmed in KEGG plant hormone signal transduction where genes related to synthesis and regulation of the auxin pathway were induced in rhizobiainoculated and mycorrhized control roots, but also downregulated in rhizobia-inoculated control roots (Additional file 9: Figure S6, Additional file 10: Figure S7, Additional files 11: Figure S8 and Additional file 12: Figure S9). However, in the PvRbohB-RNAi roots, the auxin pathway genes were induced in rhizobia-inoculated roots and downregulated in mycorrhized control roots (Additional file 13: Figure S10, Additional file 14: Figure S11, Additional files 15: Figure S12 and Additional file 16: Figure S13).

Cytokinins are key phytohormones that play a variety of roles in nodulation [36]; however, they are not known to make a major contribution to AM symbiosis [37]. In the control $P$. vulgaris roots inoculated with rhizobia, five genes related to the biosynthesis, activation, and degradation of cytokinins were upregulated relative to the inoculated control; however, none of these genes were induced in the PvRbohB-silenced roots (Fig. 6b). In the mycorrhized control roots, the induction of genes related to cytokinin signaling was not observed, although two such genes were repressed. By contrast, two genes (UDP-GLYCOSYLTRANSFERASE $83 A 1$ and GLUCOSYL/GLUCURONOSYL TRANSFERASE) involved in cytokinin metabolism were upregulated in the PvRbohB-RNAi roots during mycorrhization (Fig. 6b). These results demonstrate the distinct roles played by cytokinins in these symbioses.

Ethylene has been widely studied as a negative regulator of both rhizobial and mycorrhizal symbioses [38]. It negatively regulates the infection and organogenesis of determinate and indeterminate nodulating species [39-41]. In this analysis, we identified 11 upregulated and 13 downregulated genes related to the response and biosynthesis of ethylene in the control rhizobia-inoculated roots (Fig. 6c). A previous study of a pea (Pisum sativum) mutant line (E107) with altered symbiotic features and ethylene responses suggested that ethylene could be responsible for its decreased AM colonization [42]. Here, genes related to the response and biosynthesis of ethylene were also induced in control mycorrhized roots; however, none of them were downregulated. In the PvRbohB-RNAi roots, the genes involved in the biosynthesis and response of ethylene were not induced to the same extent as in the control roots, suggesting that less ethylene production and a smaller ethylene response takes place in the $P v R b o h B$-silenced roots during rhizobial symbioses (Fig. 6c). Similarly, genes involved in the ethylene response pathway were downregulated or not induced in $P \nu R b o h B$-RNAi roots inoculated with AM (Fig. 6c). These results suggest that $P v R b o h B$ plays a crucial role in the ethylene responses of $P$. vulgaris under both symbiotic processes.

\section{Validation of DEG expression by RT-qPCR}

To validate the transcriptome results, we determined the transcript abundance of 9 DEGs in the control and $P v R b o h B-R N A i$ roots under nodulation and mycorrhization conditions using RT-qPCR. As molecular markers of the nodulation process, the transcript levels of the early nodulins EARLY NODULIN4O (ENOD4O) and NODULE INCEPTION (NIN) were examined (Fig. 7a-b). These genes are upregulated during the formation of the IT and nodule primordia [43, 44]. For mycorrhization, we evaluated one upregulated gene identified in the RNA-Seq analysis, EF-HAND CALCIUM-BINDING DOMAINCONTAINING PROTEIN (EF-HANDM) (Fig. 7c). The results obtained using RT-qPCR and RNA-Seq were highly consistent (Fig. 7). The PvENOD40 and PvNIN transcript levels were significantly increased in the control rhizobiainoculated roots (Fig. 7a-b); however, these nodulins were not induced in the PvRbohB-RNAi roots, supporting our previous findings $[13,18]$. In the control roots colonized by AM, the PvEF-HANDM transcripts were significantly upregulated but were remarkably downregulated in the PvRbohB-RNAi roots (Fig. 7c).

Furthermore, under nodulation conditions, PEROXIDASE1 (PvPO1), CARBOXYLESTERASE17 (PvCES17), XYLOGLUCAN:XYLOGLUCOSYLTRANSFERASE (PvXGT), PVSAUR, and AMINOCYCLOPROPANE CARBOXYLATE OXIDASE $(P v A C C O)$ were upregulated in the control roots and downregulated in the PvRbohB-RNAi roots (Fig. 7d, f, g, i). Similarly, PvCES17, PvXGT, PvSAUR, PvACCO, and ETHYLENE RESPONSIVE TRANSCRIPTION FACTOR1 (PvERF1) were upregulated in the mycorrhized control roots but downregulated in the mycorrhized $P v R b o h B$-silenced roots (Fig. $7 \mathrm{e}-\mathrm{i}$ ). These results showed a strong correlation with the transcriptome data (Additional file 17: Figure S14), supporting our 


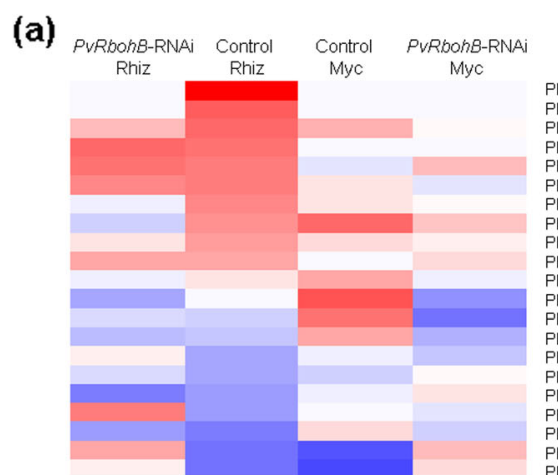

(b)

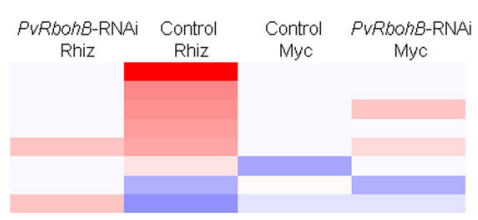

(c)

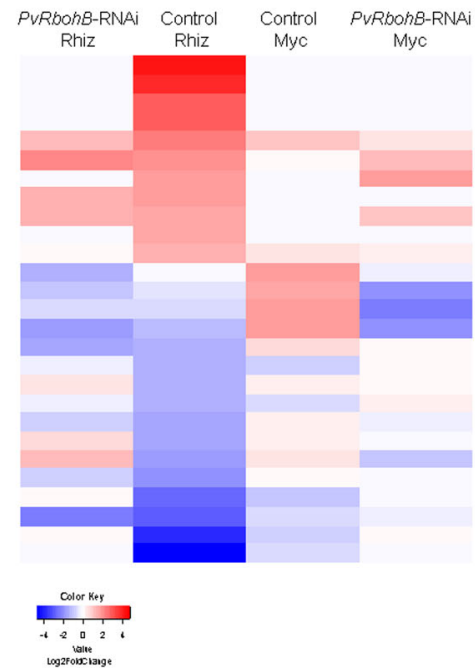

Id Gene

Phvul.007G219600.1. p Auxin-responsive protein SAUR32 Phvul.003G124600.1. p Auxin-responsive protein IAA31 Phvul.00G 0 (1)

Phvul. 011 G153400.1.p Indole 3 acetic acid amido synthetase GH3.5 related

Phvul.001G156600.1.p Auxin-induced protein AUX28

Phvul.010G117500.1.p Auxin-responsive protein SAUR32

Phvul.007G197700.1p pormancy-associated protein homolog 3 DRMH1

Phvul.003G029200 1.pp Protein PIN-LIKES 2 (PILS2)

Phvul. $010 G 003600.1$. p Auxin transporter-like protein 4

PhvU101191747001 PAwin-responsive protein SAUR32

Phvul.011G174700.1.p Auxin responsive protein (Auxin inducible)
Phyul 0055111000.1 .

Phvul. $0056173000.1 \mathrm{p}$ A Auxin-responsive protein 1 AA17

Phvul. 0036167700.1 .1 . Auxin-responsive protein AA13

Phvul.003G128800.1p.p Auxin response factor 7 (ARF7)

Phvul. 0036012600.1 .9 Auxin response factor 30 related

Phvul.0025083100.1.p Indole-3-acectic acid-amido synthetase GH3.I

Phvul.005G 172900.1.p Auxin-Induced protein 22C

Phvul.0016168000.1.p Indole-3-pyrruvate monooxygenase YucCA5 related

ld Gene

Phvul.009g231800.1.p Cytokinin dehydrogenase 2 (CKX2)

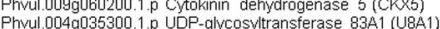

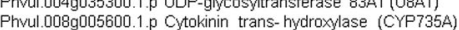

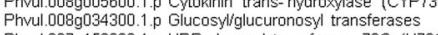

Phvul.007g 152800.1.p UDP-glucosyl transferase $73 C$ (U73C4)

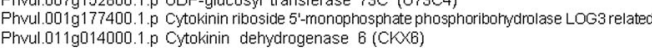

Id Gene

Phvul.010G159500.1.p Ethylene responsive transcription factor ERF003 Phvul. 00161118001.9 E Ethylene-responsive transcription factor RAP2-11
Phivu. $0046081200.1 . p$ Ethylene-responsive transcription factor RAP2-11 Phvul.0106050600.1.p Ethylene responsive transcription factor 2 Phvul.006G144900.1.p 1-aminocyclopropane-1-carboxylate oxidase Phvul.008G046400.1.p Ethylene responsive transcription factor 1 Phvul.008G214200.1.p 1-aminocyclopropane-1-carboxylate oxidase Phivul.003G042000.1.p Ninja-famly proteln AFP2

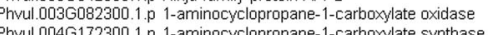
Phuvi.0016160100.1.0 Ethylene responsive transcriotion factor ERF 298 Phvul.0076193700.1.p Ethylene responsive transcription factor 1 (ERF1) Phvul.002G304200.1.p 1-aminocyclopropane-1-carboxylate oxidase Phvul.002G253900.1.p Ethylene insensitive 3-like 4 protein related (EIL4) Phvul.007G193800.1.p Ethylene responsive transcription factor 1 (ERF1) Phyul.00762 17800.1.p Ethylene-responsive transcription factor RAP2-3 Phivul.008626213800.1. p Aminocyclopropanecarboxylate oxidase (E1.14.17.4)

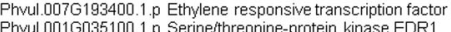

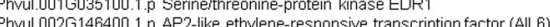

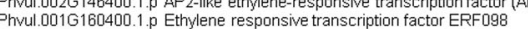
Phvul.009G123300.1.p Ethylene responsive transcription factor ERF014 Phivul.004G092100.1.p Ethylene responsive transcription factor 15 related Phvul.010G103900.1.p 1-aminocyclopropane-1-carboxylate synthase-like protein

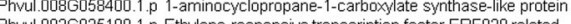
Phwil.002G035100.1.p Ethylene responsive transcription factor ERF 020 related
Phvul.002G00800.1.p 1-aminocyclopropane-1-carboxdate synthase 4 related

Fig. 6 Heatmap of the expression patterns of genes involved in phytohormone metabolism. DEGs related to the auxin (a), cytokinin (b), and ethylene (c) signaling pathways in the control and PvRbohB-RNAi P. vulgaris roots, at 7 dpi with rhizobia or AM. The color bars represent the Log2FoldChange of the DEGs, with red and blue representing the upregulated and downregulated genes, respectively. A cutoff threshold of Log2FC $\geq 1.5$ and $P$-adj/FDR $\leq 0.05$ was used

analysis of the involvement of $P \nu R b o h B$ in regulating ROSscavenging, cell wall, and phytohormone-related genes.

\section{Discussion}

Root nodule symbiosis triggers a vast transcriptional response, while AM symbiosis has a moderate response in $P$. vulgaris transgenic roots at the early stages of colonization

Plants promote associations with a wide variety of microorganisms that result in beneficial interactions to both partners. The most studied symbiotic interactions are those between legumes and nitrogen-fixing rhizobial bacteria and between plants and AM with different objectives and strategies [45]. Numerous investigations based on gene expression profiles have aimed to decipher the functional mechanisms that rhizobial and AM symbioses establish with legumes [20-27]. However, the early stages of rhizobia-inoculated and AM roots have not been studied as much. In this work, we analyzed and compared the transcriptomic profile of rhizobialinoculated and mycorrhized roots during the early stages of both symbioses (7 dpi). Our data show that rhizobial symbiosis triggers a vast transcriptional response in the first 7 days after inoculation while AM symbiosis has a more moderate response (Fig. 2); however, the opposite scenario was previously observed at the later stages of symbiosis, when $P$. vulgaris roots had 3219 DEGs at 14 dpi but only 2645 DEGs under nodulation conditions 

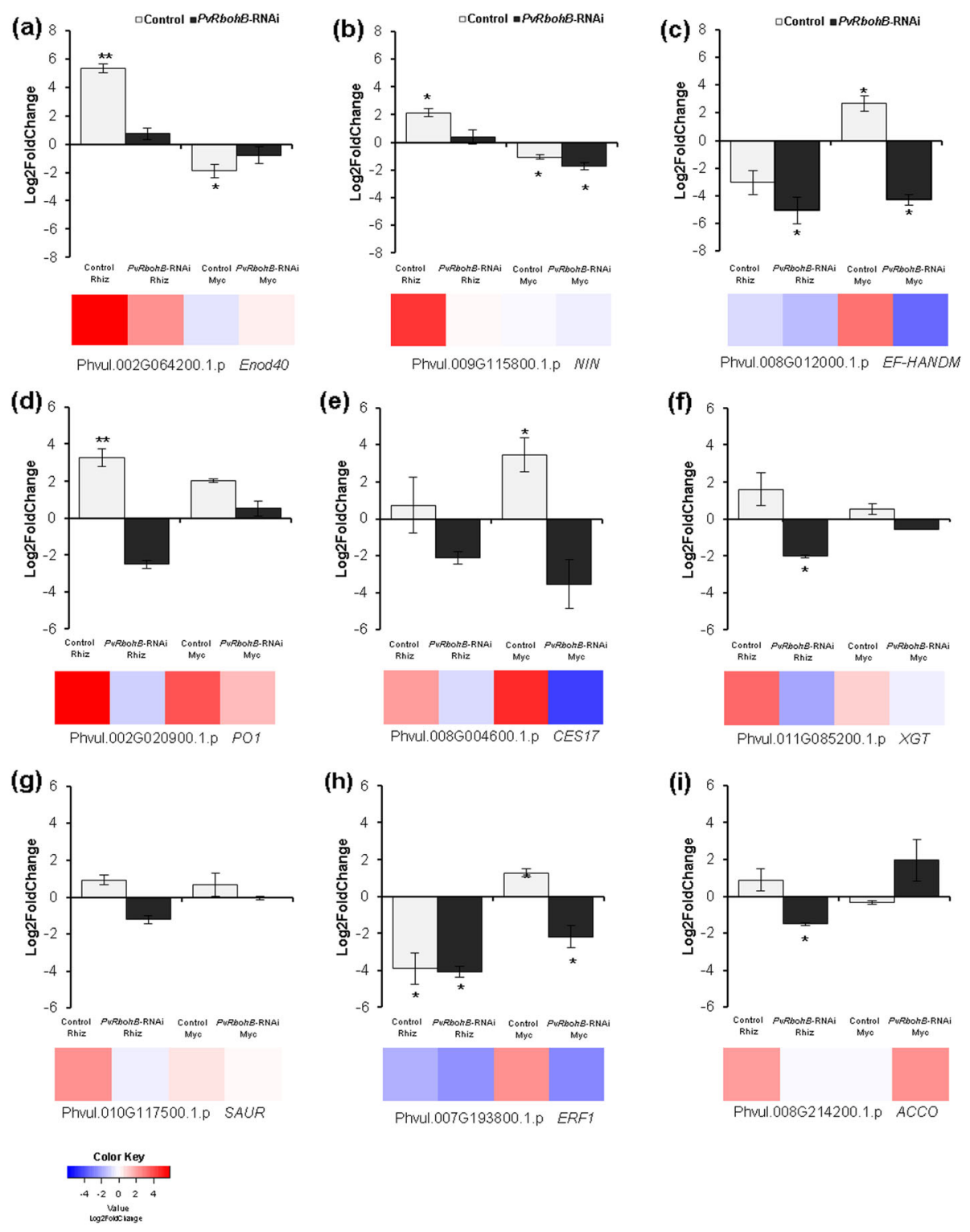

Fig. 7 Validation of the expression patterns of genes induced in control and PVRbohB-RNAi roots. The expression levels of PVENOD40 (a), PVNIN (b), PVEF-HANDM (c), PVPO1 (d), PVCES17 (e), PVXGT (f), PVSAUR (g), PVERF1 (h), and PVACCO (i) were evaluated using RT-qPCR in P. vulgaris transgenic roots at $7 \mathrm{dpi}$ with AM or rhizobia. The heatmaps of the expression of the corresponding genes, obtained using RNASeq, are shown below the graphs (a-i). The RT-qPCR data were normalized to the expression of PvEFla. The RT-qPCR bars are the means \pm SE of at least two independent biological replicates, with three technical repeats $(n>10)$. The asterisks represent statistically significant differences between the noninoculated and inoculated samples, as revealed using an unpaired Student's $t$-test $\left({ }^{*} P<0.05 ;{ }^{* *} P<0.01\right)$. The color bars of the heatmaps represent the Log2FoldChange, where red and blue represent the upregulated and downregulated genes, respectively

[25]. In bird's foot trefoil (Lotus japonicus) roots, previously generated transcriptomic data indicated that 3248 DEGs were present at 12 dpi with Mesorhizobium loti, while 3641 DEGs were detected in AM roots at $27 \mathrm{dpi}$, of which only 275 overlapped with the rhizobialsymbiosis DEGs [23]. The low number of genes with differential expression patterns between nodulation and mycorrhization at $7 \mathrm{dpi}$ contrasts with the numerous
DEGs previously detected at $14 \mathrm{dpi}$ [25]. The lag in the kinetics of these symbiotic processes could partially explain this difference. Additionally, root nodule symbiosis involves the biogenesis of a nitrogen-fixing organ, while only a few cortical cell divisions have been observed in response to AM in wild-type roots $[5,46]$. Furthermore, the most prominent functional categories assigned to upregulated genes in rhizobia-inoculated roots were, in 
contrast, assigned to the downregulated genes in the mycorrhized roots, suggesting a differential effect for these biological processes (Additional file 6: Figure S3).

\section{PvRbohB silencing causes transcriptomic changes in $P$. vulgaris with and without symbionts}

RBOHs, plant NADPH oxidases, are one of the specific enzymes that produce ROS in plants. An increasing body of evidence indicates that ROS production by RBOHs is involved in the regulation of root hair and primary root growth [47]. Loss-of-function studies of several RBOHs resulted in a reduction in primary root growth in Arabidopsis $[48,49]$. Particularly, $P v R b o h B$ silencing showed a marginal reduction in the growth of the main root and a significant reduction in lateral root density [13]. In this work, the expression levels of the cell wall-remodeling genes, as well as genes involved in the cell cycle and the biosynthesis of and response to auxins, were considerably downregulated in the $P v R b o h B$-silenced roots (Fig. 2b). These results are consistent with the $15 \%$ reduction in lateral root density, as well as the differences in lateral root lengths detected in $P v R b o h B-$ RNAi roots at 1 to 7 days postemergence [13, 28], confirming that $P v R b o h B$ is an important component of growth and development in $P$. vulgaris roots.

Under symbiotic conditions, PvRbohB silencing affected the expression of approximately half the number of DEGs in the nonsilenced roots under nodulation and mycorrhization conditions. In rhizobial-inoculated roots, $20 \%$ of the induced genes in control roots were upregulated in $P v R b o h B-$ RNAi roots, while in mycorrhized roots, only $0.7 \%$ exhibited a similar response in PvRbohB-RNAi roots. These results suggest that $P \nu R b o h B$ silencing had a more drastic impact on the transcriptome changing of the initial steps of AM. Consistent with these results, a significant repression of gene expression was observed during the initial stages of rhizobial infection and AM colonization in M. truncatula transgenic roots with silenced $M t R O P 9 i$ relative to the control [50]. By contrast, a transcriptome analysis performed on the roots of $M$. truncatula inoculated with $S$. meliloti revealed that the expression of $67 \%$ of the genes required for the symbiosis were affected by a treatment with diphenylene iodonium, an inhibitor of ROS production [51]. Furthermore, several genes involved in cell wall remodeling, early nodulins, and biosynthesis of and response to phytohormones such as auxins and ethylene had an opposite expression pattern between rhizobial-inoculated and mycorrhized control roots against $P v R b o h B$-RNAi inoculated roots. Likewise, transcription factors such as WRKYs which can function up- and downstream of hormones and control developmental processes via auxins, cytokinins, and brassinosteroids [52]. Our data strongly suggest that $P v R b o h B$ plays a central role in cell wall remodeling and the response to phytohormones under symbiotic conditions.

\section{Cell wall remodeling affected by PvRbohB-RNAi roots} during rhizobial and $A M$ symbioses

ROS are oxygen products that play dual roles in plants, both as toxic compounds and as key regulators of many biological processes [53]. ROS produced by RBOHs have shown to have specific effects in legume-rhizobia and mycorrhizal symbioses [13, 14, 17, 18, 50]. Particularly, studies of $P v R b o h B$-silenced transgenic bean roots revealed a positive impact during the early stages of AM and a negative impact in rhizobial symbiotic processes in P. vulgaris [13, 14, 18]. In addition, ROS have been detected during IT growth and the formation of nodule primordia in alfalfa (Medicago sativa) [54]. Recently, it was observed that the suppression of the immune system by a calcium-dependent protein kinaseRboh complex is required for rhizobial colonization in M. truncatula [55]. ROS production is a component of the early nodulation signaling pathway initiated by the perception of Nod factors [16, 40, 56-58]. This process is accompanied by the expression of class-III peroxidases $[56,59,60]$, which have two catalytic activities (peroxidative and hydrolytic) that enable them to either generate $\mathrm{ROS}\left({ }^{\circ} \mathrm{OH}\right.$ and $\mathrm{HOO}^{\circ}$ ) or decrease ROS levels by sequestration of hydrogen peroxide during polymerization of the cell wall [61]. In this work, we observed that $P v R b o h B$ silencing affects the expression of a large number of peroxidases in rhizobia-inoculated and mycorrhized roots (Fig. 5a), indicating that $P v R b o h B$ plays a crucial role during ROS-mediated signaling in both symbiotic processes. In addition, genes involved in cell wall biogenesis presented a differential expression in control and PvRbohB-silenced transgenic roots under both symbiotic processes (Fig. 5b). In rhizobial-inoculated roots, $P v R b o h B$ silencing induced some cell wall biogenesis genes that were downregulated in the control roots, such as those encoding GLYCOSYLTRANSFERASE, CELLULOSE SYNTHASE, and BETA-1,4-MANNOSYL-GLYCOPROTEIN 4-BETA- $N$ ACETYLGLUCOSAMINYL TRANSFERASE. The last of these proteins is one of the most important enzymes involved in the regulation of glycoprotein oligosaccharide biosynthesis. It catalyzes the addition of $\mathrm{N}$-acetylglucosamine in a beta 1-4 linkage to the beta-linked mannose of the trimannosyl core of the $\mathrm{N}$-linked sugar chains, altering not only the composition, but also the conformation, processing, and elongation of the $\mathrm{N}$-glycan molecule $[62,63]$. The effect of $P \nu R b o h B$ silencing on the transcriptional response of this battery of genes supports the defects observed in the nodulation program of the RbohBRNAi roots [13]. Several Rboh members are known to be important players in the developmental programs of different tissues and organs in a variety of plant species $[47-49,64]$. 


\section{PvRbohB silencing affects phytohormone-related genes under symbiotic conditions}

The plant hormone auxin is crucial to all aspects of plant growth and development. In legumes, auxin biosynthesis and signaling occur during the formation of the IT [65]. Auxin-responsive and signaling components, such as SMALL AUXIN UP RNA1 (SAUR1), GRETC HEN HAGEN3.1 (GH3.1), AUXIN RESPONSE FACTOR $16 a$ (ARF16a), and INDOLE-3-ACETIC ACID INDUCIBLE9 (IAA9), were induced in M. truncatula root hairs at 1 to 5 dpi with $S$. meliloti $[39,66]$. Here, we also observed the induction of the early auxin response genes, such as SAUR32/71, GH3.5, and IAA28, in the rhizobia-inoculated roots; however, ARF7 and GH3.1/3.6 were repressed, suggesting a differential role for these genes in P. vulgaris. Approximately $45 \%$ of the auxinrelated genes observed in the rhizobia-inoculated control roots presented different expression patterns in the PvRbohB-RNAi roots, including SAUR32, IAA13, and $D R M H 1$ (Fig. 6a). However, the role of auxins in mycorrhizal symbioses is not clear, as biochemical and molecular studies have revealed variable levels of auxins and auxin-related molecules throughout these processes [37, 67-69]. Studies using auxin mutants have suggested that auxin perception is required for arbuscule development and the establishment of mycorrhizal symbiosis, at least for modulating strigolactone levels during this process [70]. Similar to our observations in the rhizobiainoculated roots, the early auxin response genes, such as IAA17, GH3.6, and SAUR32/71, were induced in the mycorrhized control roots, while ARF7 was repressed (Fig. 6a). The auxin-regulated protein GH3 and other transcripts encoding putative auxin response factors were induced during the colonization of rice (Oryza sativa) and $M$. truncatula roots by Rhizoglomus irregulare [71, 72]; however, in contrast to our data, an $A R F$ (ARF18) transcript was previously reported to be induced in sunflower (Helianthus annuus) roots during colonization by $R$. irregulare [73]. PvRbohB-RNAi abolished the differential expression levels of these genes in both the root nodule and AM symbioses, although genes such as GH3.1 were induced in the rhizobia-inoculated roots (Fig. 6a). Similarly, homologs of the auxin transporter AUX1-like genes were found to be slightly induced by rhizobial infection in $P$. vulgaris, but not in PvRbohA-RNAi roots [74]. These data suggest that $P v R b o h B$ has an important function in the regulation and response to auxin in both microbial symbioses.

The cytokinins are essential for nodule organogenesis, a process that is orchestrated by the CYTOKININ DEHYDROGENASES (CKXs) in L. japonicus [75-77]. In this study, $P v C K X 2$ and $P v C K X 5$ were induced in the rhizobia-inoculated control roots, confirming the role of the cytokinins at the early stages of nodulation in $P$. vulgaris (Fig. 6b). These genes were downregulated in the $P v R b o h B$-silenced roots, however, in which only CKX6 and GLUCOSYL/GLUCURONOSYL TRANSFER$A S E$ were upregulated, suggesting a crucial role for $P v R b o h B$ in regulating cytokinin biosynthesis during nodulation in $P$. vulgaris. Nevertheless, a studies involving the CYTOKININ RESPONSE1 (CRE1) cytokinin receptor mutant in $M$. truncatula have suggested that the cytokinins may be less critical for AM colonization [37]. Our data generally support this conclusion, but also show that $P v R b o h B$ plays a role in the biosynthesis of cytokinins during $P$. vulgaris-AM symbiosis. This difference between symbioses may be partially due to the central role that cytokinins play in the orchestration of cell division during nodulation, which is not required for mycorrhizal colonization. This nodulation-related mitosis was affected in the PvRbohB-RNAi transgenic roots, which showed a drastic reduction in mitotic activity compared to the infected control roots [13], which are not required for mycorrhizal colonization.

Cytokinin signaling displays broad interactions with other hormone signaling pathways, such as ethylene. Cytokinin can stimulate the production of ethylene [78], which is a negative regulator of both rhizobial and mycorrhizal symbioses [38]. In this work, genes involved in the biosynthesis and response of ethylene presented differential expression in control and PvRbohA-RNAi roots (Fig. 6c). Particularly, the homologs of two key ethylene biosynthesis regulators, 1-AMINOCYCLOPROPANE-1-CARBOXYLATE (ACC) SYNTHASE and ACC $O X I D A S E$, were upregulated in the control roots, confirming previous reports of an increase in ethylene production during the early stages of nodulation in $P$. vulgaris [41, 79-81]. Similarly, in mycorrhized roots, the homologs of ACC OXIDASE were upregulated under control and $P v R b o h B$ silencing conditions. By contrast, the expression levels of several other homologs of these genes were repressed at the same time point, indicating a complex regulation of ethylene metabolism in this legume. Our results confirm the central role of auxins, cytokinins, and ethylene in the nodulation and mycorrhization processes in P. vulgaris and suggest that $P v R b o h B$ could be an important player in the homeostasis of these phytohormones in both microbial symbioses.

\section{Conclusions}

In this article, we present a comparative transcriptome analysis of the $P$. vulgaris control and PvRbohB-RNAi roots inoculated with rhizobia and AM fungi. Our results indicate that root nodule symbiosis induce considerable transcriptomic changes, with the AM fungi inducing less of a response than rhizobia during the early stages of their respective $P$. vulgaris symbioses. Additionally, a compendium of DEGs related to ROS 
scavenging, cell wall remodeling, and phytohormone homeostasis during nodulation and mycorrhization in $P$. vulgaris were found to be affected by $P v R b o h B$ silencing. These results provide important information on the symbiotic gene signaling networks involved in the early stages of rhizobial and mycorrhizal colonization as well as the differential effects of a NADPH oxidase gene, $R b o h B$, on these processes.

\section{Methods}

Plant materials, microsymbiont inoculation, and growth conditions

Mesoamerican $P$. vulgaris cv. Negro Jamapa was obtained from the local market. Transgenic PvRboh-RNAi and nonsilenced (control) roots were generated in a transformation using Agrobacterium rhizogenes K599 under laboratory conditions according to Instituto de Biotecnología-UNAM guidelines [13]. The composite plants were transferred into pots and inoculated with the respective microsymbionts. The roots were inoculated with Rhizophagus irregularis (800 spores per plant; INI-FAP biofertilizer, produced at Campo Experimental Rosario Izapa, Chiapas, Mexico) or Rhizobium tropici (strain CIAT899; $1 \mathrm{ml}$ per seedling at $\mathrm{OD}_{600}=0.05$ ) with the same conditions used previously $[13,18]$. The plants inoculated with $R$. irregularis were irrigated twice a week with half-strength $B \& D$ solution [82] containing a low concentration of potassium phosphate $\left(10 \mu \mathrm{M} \mathrm{K} \mathrm{K}_{2} \mathrm{HPO}_{4}\right)$ to facilitate AM colonization [83]. To promote nodulation, the composite plants inoculated with rhizobia were watered with $\mathrm{B} \& \mathrm{D}$ medium without nitrate $\left(\mathrm{KNO}_{3}\right)$, while the noninoculated plants $(n=10$ per biological replicate) were irrigated with $B \& D$ solution supplemented with $8 \mathrm{mM}$ potassium nitrate to prevent nodulation. At $7 \mathrm{dpi}$, the roots $(n=5-10$ per condition) were harvested for RNA isolation, immersed in liquid nitrogen, and stored at $-80^{\circ} \mathrm{C}$ until use. Before freezing, a section of each transgenic root was analyzed under the microscope to confirm fungal colonization $(R$. irregularis) or bacterial infection ( $R$. tropici). Noreide Nava undertook the formal identification of the plant material used in this work under our laboratory conditions.

\section{RNA extraction, library preparation, and sequencing}

For the transcriptome profiling, high-quality total RNA was isolated from the frozen tissues of three biological replicates with 30-5 plants using a ZR Plant RNA MiniPrep kit following the manufacturer's instructions (Zymo Research, Irvine, CA, USA). Any contamination from genomic DNA was eliminated by incubating the samples

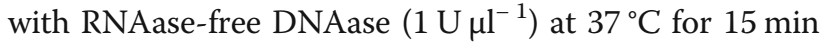
and at $65^{\circ} \mathrm{C}$ for $10 \mathrm{~min}$. The RNA integrity numbers (RINs) [84] and the concentrations of the RNA samples were determined using an Agilent 2100 Bioanalyzer platform (Agilent Technologies, Santa Clara, CA, USA) with a Nano 6000 kit (Thermo Fisher Scientific, Waltham, MA, USA). Only samples with RIN values of 8.0 or above were used for the RNA-Seq analysis. cDNA libraries were individually generated for each sample using the TruSeq RNA-Seq Sample Prep kit (Illumina, San Diego, CA, USA), following the manufacturer's protocol. Libraries were sequenced as $75-$ to $100-\mathrm{bp}$ paired-end reads using an Illumina HiSeq 2000.

\section{RT-qPCR assays}

To validate the RNA-Seq results, an RT-qPCR analysis was performed for a selection of highly upregulated or downregulated genes. High-quality total RNA was isolated from the frozen root tissues using a ZR Plant RNA MiniPrep kit (Zymo Research), following the manufacturer's instructions. The integrity of the RNA was confirmed using gel electrophoresis, and the RNA concentration was determined with a NanoDrop2000 spectrophotometer (Thermo Fisher Scientific, Waltham, MA, USA). Any genomic DNA was removed using RNAase-free DNAase (1 U $\mathrm{\mu l}^{-1}$; Roche, Basel, Switzerland), following the manufacturer's recommendations. The RT-qPCR analysis was performed using a Maxima SYBR Green/Fluorescein qPCR kit (Thermo Fisher Scientific), according to the following instructions: each reaction contained $7.5 \mu$ l Maxima SYBR Green/Fluorescein qPCR Master Mix (2X) (Thermo Scientific, USA), $0.5 \mu \mathrm{l}$ cDNA samples, and $0.45 \mu \mathrm{l}$ of each primer $(10 \mu \mathrm{M})$ in a reaction system of $15 \mu$ l. The thermal cycle was as follows: $95^{\circ} \mathrm{C}$ for $10 \mathrm{~min}, 40$ cycles of $95^{\circ} \mathrm{C}$ for $15 \mathrm{~s}, 60^{\circ} \mathrm{C}$ for $30 \mathrm{~s}$, and $72^{\circ} \mathrm{C}$ for $30 \mathrm{~s}$. To corroborate the absence of contaminant DNA, a control sample without reverse transcriptase was included. The relative expression values were determined using the formula $2^{-\mathrm{CT}}$, where the cycle threshold value $\mathrm{CT}$ is equal to the $\mathrm{Ct}$ of the gene of interest minus the $\mathrm{Ct}$ of the reference gene, $P$. vulgaris EF1 $\alpha$ [85]. At least two biological replicates were performed, and each dataset was generated using three technical repeats. The gene-specific oligonucleotides used for the RT-qPCR analysis are listed in Additional file 3: Table S3.

\section{Alignment and data analysis}

To estimate the transcript abundance in each condition, the sequence quality was analyzed using FastQC software (www.bioinformatics.babraham.ac.uk/projects). The high-quality paired-end reads were mapped onto the $P$. vulgaris G19833 genome, obtained from the National Center for Biotechnology Information (NCBI) Genome database (Assembly GCA_000499845.1; https://www. ncbi.nlm.nih.gov/genome/380?genome_assembly_id $=485$ 90), using the BWA software package for mapping lowdivergence sequences ([86]; http://bio-bwa.sourceforge. net). We used the "bwa mem" command to align the 
reads with default parameters. For each sample, both paired ends were run together; only the samples from the transgenic PvRboh-RNAi roots inoculated with $R$. tropici were mapped as single-end reads. The aligned sequencing reads were counted using htseq-count, a Python script with default parameters that taked as input a Binary Alignment Map (BAM) file and a General Feature Format (GFF) file with gene models [87]. To evaluate the intrinsic variability within the data groups, a multidimensional scaling (MDS) ordination method was used, which graphically displays the dissimilarities between the samples. Also, the Pearson's correlation coefficients between the replicates were estimated using the cor function of the ggpubr package and plotted with the function ggplot of the ggplot2 package all in $\mathrm{R}$ to confirm the clustering observed in the MDS plots. The results shown reflect at least two biological replicates for each treatment.

The DEGs were identified using the software packages DESeq [88], NOIseq, and edgeR [89], which offer an exact statistical test. A counts per million (CPM) of 5 and a $\log _{2}$ fold change (Log2FoldChange) $\geq 1.5$ with a false discovery rate (FDR) or P-adjusted $\leq 0.05$ was used as a cutoff for the identification of upregulated and downregulated genes. This analysis was subsequently summarized in a MAPlot, in which the significance of the differential expression results is compared to the Log2FoldChange values and the mean number of normalized counts per gene. These analyses were performed using Integrated Differential Expression Analysis MultiEXperiment [90].

Additionally, the DEGs were functionally annotated using the Blast2GO software ([88], https://www.blast2go. $\mathrm{com} /$ ), supported by GO terms, InterPro domains, and enzyme codes. A GO term overview was performed using a GO-slim analysis implemented in Blast2GO software using the UniProt database [91]. The pathway annotations were based on the Kyoto Encyclopedia of Genes and Genomes (KEGG) pathway (www.genome.jp/ kegg) [92]. The distribution and abundance (Log2FoldChange) of these genes were presented in Venn diagrams using the function draw.quad.venn in the VennDiagram package in $\mathrm{R}$ and in heatmaps with the function heatmap. 2 of the gplot package in $\mathrm{R}$, respectively. An unpaired Student's $t$-test was performed using the $t$.test function of the stats package in R.

\section{Supplementary information}

Supplementary information accompanies this paper at https://doi.org/10. 1186/s12864-019-6162-7.

Additional file 1: Table S1. Statistical quality control analysis of the raw sequence data, performed using FastQC software.

Additional file 2: Table S2. Statistics of the reads for each condition mapped onto the reference genome of $\mathrm{P}$. vulgaris using the BurrowsWheeler Aligner (BWA).
Additional file 3: Table S3. Genespecific oligonucleotides used in this study.

Additional file 4: Figure S1. Intrinsic variability within the data groups. Multidimensional Scaling plots (MDS) (a-c) and Pearson correlation (d-f) of the different replicas per condition of control and PVRbohB-RNAi samples of the transcriptome uninoculated $(\mathbf{a}, \mathbf{d})$, inoculated with rhizobia (b, e), and inoculated with AM (c, f). Ctrl: control roots; Bi: PvRbohB-RNAi; Rhiz: inoculated with R. tropici; Myc: inoculated with $R$. irregularis; 1: replicate 1; 2: replicate 2; 3: replicate 3 .

Additional file 2: Figure S2. Functional annotation of the DEGs in rhizobia-inoculated (Rhiz) and mycorrhized (Myc) roots of $P$. vulgaris. The bars show the percentages of the upregulated $(\mathbf{a}, \mathbf{c}, \mathbf{e})$ and downregulated (b, d, f) DEGs annotated with GO terms for the functional categories of biological processes (a-b), molecular functions $(\mathbf{c}-\mathbf{d})$, and cellular components (e-f). A cutoff threshold of $\log 2 F C \geq 1.5$ and P-adj/FDR $\leq 0.05$ was used, and GO terms were assigned using a GO-Slim analysis of the UniProt database in Blast2GO.

Additional file 6: Figure S3. Functional annotation of the DEGs in the PvRbohB-RNAi roots in nonsymbiotic conditions of $P$. vulgaris. Functional annotation of the upregulated and downregulated DEGs annotated with $\mathrm{GO}$ terms of the functional categories of biological processes (a), molecular functions (b), and cellular components (c). A cutoff threshold of $\log 2 F C \geq 1.5$ and P-adj/FDR $\leq 0.05$ was used, and GO terms were assigned using a GO-Slim analysis of the UniProt database in Blast2GO.

Additional file 7: Figure S4. Functional annotation of the DEGs in rhizobia-inoculated and mycorrhized PVRbohB-RNAi roots, relative to the control. The bars show the percentages of upregulated $(\mathbf{a}, \mathbf{c}, \mathbf{e})$ and downregulated $(\mathbf{b}, \mathbf{d}, \mathbf{f})$ DEGs annotated with GO terms of the functional categories of biological processes $(\mathbf{a}-\mathbf{b})$, molecular functions $(\mathbf{c}-\mathbf{d})$, and cellular components (e-f). A cutoff threshold of $\log 2 \mathrm{FC} \geq 1.5$ and P-adj/ FDR $\leq 0.05$ was used, and GO terms were assigned using a GO-Slim analysis against the UniProt database in Blast2GO.

Additional file 8: Figure S5. Transcript levels of $P \vee R b o h B$ in the control and PvRbohB-RNAi roots used in this study. The plot includes RNA-Seq data and validating RT-qPCR data. Bars indicate the means \pm SE.

Additional file 9: Figure S6. KEGG pathway map of plant hormone signal transduction for upregulated genes in rhizobia-inoculated control roots.

Additional file 10: Figure S7. KEGG pathway map of plant hormone signal transduction for downregulated genes in rhizobia-inoculated control roots.

Additional file 11: Figure S8. KEGG pathway map of plant hormone signal transduction for upregulated genes in mycorrhized control roots.

Additional file 12: Figure S9. KEGG pathway map of plant hormone signal transduction for downregulated genes in mycorrhized control roots.

Additional file 13: Figure S10. KEGG pathway map of plant hormone signal transduction for upregulated genes in rhizobia-inoculated PvRbohB-silenced roots.

Additional file 14: Figure S11. KEGG pathway map of plant hormone signal transduction for downregulated genes in rhizobia-inoculated PvRbohB-silenced roots.

Additional file 15: Figure S12. KEGG pathway map of plant hormone signal transduction for upregulated genes in mycorrhized PvRbohBsilenced roots.

Additional file 16: Figure S13. KEGG pathway map of plant hormone signal transduction for downregulated genes in mycorrhized PvRbohBsilenced roots

Additional file 17: Figure S14. Correlation of the RNA-seq data and RT-qPCR expression profiles. The mean transcriptional changes (Log2FoldChange) of ROS-scavenging, cell wall, and phytohormone-related genes between the rhizobial-inoculated (a) and AM (b) roots at $7 \mathrm{dpi}$.

\section{Abbreviations}

AM: Arbuscular mycorrhizal; BAM: Binary alignment map; BP: Biological process; CC: Cellular component; CPM: Count per million; DEG: Differential expressed genes; FDR: False discovery rate; GO: Gene ontology; IT: Infection thread; KEGG: Kyoto Encyclopedia of Genes and Genomes; 
MDS: Multidimensional scaling; MF: Molecular function; NCBI: National Centre for Biotechnology Information; RBOH: Respiratory burst oxidase homologs; RNAi: RNA interference; ROS: Reactive oxygen species; RT-qPCR: Reversetranscription quantitative of polymerase chain reaction; SAM: Sequence alignment map; SYMRK: Symbiosis receptor kinase/does not make infections 2

\section{Acknowledgments}

We are grateful to Dr. Enrique Merino for discussing the results and for providing the computational server for bioinformatic analysis. The authors also thank LCG José Damián Martínez Reyes for his contribution to the bioinformatic analysis of some of the sequences obtained in this project. We also acknowledge the support of Drs. Alejandro Sánchez, Ricardo Grande, and Verónica Jiménez from Unidad de Secuenciación Masiva y Bioinformática, Instituto de Biotecnología, UNAM, respectively.

\section{Authors' contributions}

CQ and FS conceived the study. CF, AZ, and JM analyzed the data. NN performed the extraction and purification of the RNA, the CDNA synthesis, and the RT-qPCR experiments. CQ, JM, and CF drafted, edited, and revised the manuscript. All authors read and approved the final manuscript.

\section{Funding}

Funding was provided by the Universidad Nacional Autónoma de México (UNAM), under a DGAPA grant (IN204115) to C.Q. and a DGAPA postdoctoral fellowship to C.F.G. Funding was also provided by Consejo Nacional de Ciencia y Tecnología in Mexico (CONACyT), under Fronteras de la Ciencia (FC) grant: FC-2016/1503. UNAM-DGAPA and CONACYT-FC were not involved in the design of the study, collection, analysis, and interpretation of data and in writing the manuscript.

\section{Availability of data and materials}

The data were deposited in the NCBI databases under the BioProject accession number PRJNA482464, the BioSample accession numbers SAMN09831769-SAMN09831794, and the Sequence Read Archive accession numbers SRR7693915-SRR7693917, SRR7696192-SRR7696194, SRR7696200SRR7696202, SRR7696204-SRR7696206, SRR7696589-SRR7696591, and SRR7696208-SRR7696210.

\section{Ethics approval and consent to participate}

Mesoamerican P. vulgaris cv. Negro Jamapa was obtained from the local market. No specific permits were required for plant collection. The study did not require ethical approval or consent as no endangered or protected plant species were involved.

\section{Consent for publication}

Not applicable.

\section{Competing interests}

The authors declare that they have no competing interests.

\section{Author details}

'Departamento de Biología Molecular de Plantas, Instituto de Biotecnología, Universidad Nacional Autónoma de México, Avenida Universidad 2001, Colonia Chamilpa, Cuernavaca, Morelos 62210, Mexico. ${ }^{2}$ Department of Molecular Biology and Genetics, Aarhus University, C 8000 Aarhus, Denmark.

Received: 19 April 2019 Accepted: 9 October 2019

Published online: 04 November 2019

\section{References}

1. Ågren Gl, Wetterstedt JÅM, Billberger MFK. Nutrient limitation on terrestrial plant growth - modeling the interaction between nitrogen and phosphorus. New Phytol. 2012;194:953-60. https://doi.org/10.1111/j.14698137.2012.04116.x.

2. Jia Y, Gray VM, Straker CJ. The influence of rhizobium and arbuscular mycorrhizal fungi on nitrogen and phosphorus accumulation by Vicia faba. Ann Bot. 2004;94:251-8.

3. Maillet $F$, Poinsot $V$, André $O$, Puech-Pagés $V$, Haouy A, Gueunier M, et al. Fungal lipochitooligosaccharide symbiotic signals in arbuscular mycorrhiza. Nature. 2011;469:58-64.
4. Paszkowski U. A journey through signaling in arbuscular mycorrhizal symbioses. New Phytol. 2006;172:35-46.

5. Downie JA. Legume nodulation. Curr Biol. 2014;24:R184-90. https://doi.org/ 10.1016/..cub.2014.01.028.

6. Sieberer BJ, Chabaud M, Fournier J, Timmers ACJ, Barker DG. A switch in $\mathrm{Ca} 2+$ spiking signature is concomitant with endosymbiotic microbe entry into cortical root cells of Medicago truncatula. Plant J. 2012;69:822-30.

7. Endre G, Kereszt A, Kevei Z, Mihacea S, Kaló P, Kiss GB. A receptor kinase gene regulating symbiotic nodule development. Nature. 2002;417:962-6.

8. Stracke S, Kistner C, Yoshida S, Mulder L, Sato S, Kaneko T, et al. A plant receptor-like kinase required for both bacterial and fungal symbiosis. Nature. 2002:417:959-62.

9. Venkateshwaran M, Jayaraman D, Chabaud M, Genre A, Balloon AJ, Maeda J, et al. A role for the mevalonate pathway in early plant symbiotic signaling. Proc Natl Acad Sci. 2015;112:9781-6. https://doi.org/10.1073/pnas. 1413762112.

10. Lévy J, Bres C, Geurts R, Chalhoub B, Kulikova O, Duc G, et al. A Putative Ca 2 and Calmodulin- Dependent Protein Kinase Required for Bacterial and Fungal Symbioses. Science. 2004;303:1361-4. https://doi.org/10.1126/ science.1093038.

11. Yano K, Yoshida S, Müller J, Singh S, Banba M, Vickers $K$, et al. CYCLOPS, a mediator of symbiotic intracellular accommodation. Proc Natl Acad Sci. 2008;105:20540-5. https://doi.org/10.1073/pnas. 0806858105.

12. Genre A, Russo G. Does a Common Pathway Transduce Symbiotic Signals in Plant-Microbe Interactions? Front Plant Sci. 2016;7:96. https://doi.org/10. 3389/fpls.2016.00096.

13. Montiel J, Nava N, Cárdenas L, Sánchez-López R, Arthikala MK, Santana O, et al. A Phaseolus vulgaris NADPH oxidase gene is required for root infection by rhizobia. Plant Cell Physiol. 2012;53:1751-67.

14. Arthikala MK, Sánchez-López R, Nava N, Santana O, Cárdenas L, Quinto C. RbohB, a Phaseolus vulgaris NADPH oxidase gene, enhances symbiosome number, bacteroid size, and nitrogen fixation in nodules and impairs mycorrhizal colonization. New Phytol. 2014;202:886-900.

15. Kirika LM, Bergmann HF, Schikowsky C, Wimmer D, Korte J, Schmitz U, et al. Silencing of the Rac1 GTPase MtROP9 in Medicago truncatula stimulates early Mycorrhizal and Oomycete root Colonizations but negatively affects Rhizobial infection. Plant Physiol. 2012;159:501-16. https://doi.org/10.1104/ pp.112.193706.

16. Montiel J, Arthikala MK, Cárdenas L, Quinto C. Legume NADPH oxidases have crucial roles at different stages of nodulation. Int J Mol Sci. 2016;17:680.

17. Marino D, Andrio E, Danchin EGJ, Oger E, Gucciardo S, Lambert A, et al. A Medicago truncatula NADPH oxidase is involved in symbiotic nodule functioning. New Phytol. 2011;189:580-92.

18. Arthikala MK, Montiel J, Nava N, Santana O, Sánchez-López R, Cárdenas L, et al. PvRbohB negatively regulates Rhizophagus irregularis colonization in Phaseolus vulgaris. Plant Cell Physiol. 2013;54:1391-402.

19. Belmondo S, Calcagno C, Genre A, Puppo A, Pauly N, Lanfranco L. The Medicago truncatula MtRbohE gene is activated in arbusculated cells and is involved in root cortex colonization. Planta. 2016;243:251-62.

20. Verdier J, Torres-Jerez I, Wang M, Andriankaja A, Allen SN, He J, et al. Establishment of the Lotus japonicus gene expression atlas (LjGEA) and its use to explore legume seed maturation. Plant J. 2013;74:351-62.

21. O'Rourke JA, Iniguez LP, Fu F, Bucciarelli B, Miller SS, Jackson SA, et al. An RNASeq based gene expression atlas of the common bean an RNA-Seq based gene expression atlas of the common bean. BMC Genomics. 2014;15:866.

22. Roux B, Rodde N, Jardinaud MF, Timmers T, Sauviac L, Cottret L, et al. An integrated analysis of plant and bacterial gene expression in symbiotic root nodules using laser-capture microdissection coupled to RNA sequencing. Plant J. 2014;77:817-37.

23. Handa Y, Nishide H, Takeda N, Suzuki Y, Kawaguchi M, Saito K. RNA-seq transcriptional profiling of an Arbuscular Mycorrhiza provides insights into regulated and coordinated gene expression in Lotus japonicus and Rhizophagus irregularis. Plant Cell Physiol. 2015;56:1490-511.

24. Song F, Li J, Fan X, Zhang Q, Chang W, Yang F, et al. Transcriptome analysis of Glomus mosseae/Medicago sativa mycorrhiza on atrazine stress. Sci Rep. 2016;6:20245. https://doi.org/10.1038/srep20245.

25. Nanjareddy K, Arthikala MK, Gómez BM, Blanco L, Lara M. Differentially expressed genes in mycorrhized and nodulated roots of common bean are associated with defense, cell wall architecture, $\mathrm{N}$ metabolism, and P metabolism. PLoS One. 2017;12:e0182328. 
26. Tromas A, Parizot B, Diagne N, Champion A, Hocher V, Cissoko M, et al. Heart of Endosymbioses: Transcriptomics reveals a conserved genetic program among Arbuscular Mycorrhizal, Actinorhizal and Legume-Rhizobial Symbioses. PLoS One. 2012;7:e44742.

27. Kelly S, Mun T, Stougaard J, Ben C, Andersen SU. Distinct Lotus japonicus Transcriptomic Responses to a Spectrum of Bacteria Ranging From Symbiotic to Pathogenic. Front Plant Sci. 2018;9:1218.

28. Montiel J, Arthikala M, Quinto C. Phaseolus vulgaris RbohB functions in lateral root development. Plant Signal Behav. 2013;8:144-6.

29. lqual N, Khan NA, Ferrante A, Trivellini A, Francini A, MIR K. Ethylene Role in Plant Growth, Development and Senescence: Interaction with Other Phytohormones. Front Plant Sci. 2017;08:475. https://doi.org/10.3389/fpls.2017.00475.

30. Lambeth JD. NOX enzymes and the biology of reactive oxygen. Nat Rev Immunol. 2004:4:181-9.

31. Liszkay A, Kenk B, Schopfer P. Evidence for the involvement of cell wall peroxidase in the generation of hydroxyl radicals mediating extension growth. Planta. 2003;217:658-67.

32. Marjamaa K, Kukkola EM, Fagerstedt KV. The role of xylem class III peroxidases in lignification. J Exp Bot. 2009;60:367-76.

33. Bapaume $L$, Reinhardt D. How membranes shape plant symbioses: signaling and transport in nodulation and arbuscular mycorrhiza. Front Plant Sci. 2012;3:223. https://doi.org/10.3389/fpls.2012.00223.

34. Xia X-J, Zhou Y-H, Shi K, Zhou J, Foyer CH, Yu J-Q. Interplay between reactive oxygen species and hormones in the control of plant development and stress tolerance. J Exp Bot. 2015;66:2839-56. https://doi.org/10.1093/jxb/erv089.

35. Orman-Ligeza B, Parizot B, de Rycke R, Fernandez A, Himschoot E, Van Breusegem $\mathrm{F}$, et al. $\mathrm{RBOH}$-mediated ROS production facilitates lateral root emergence in Arabidopsis. Development. 2016;143:3328-39. https://doi.org/ 10.1242/dev.136465.

36. Boivin S, Fonouni-Farde C, Frugier F. How auxin and cytokinin phytohormones modulate root microbe interactions. Front Plant Sci. 2016;7: 1240. https://doi.org/10.3389/fpls.2016.01240.

37. Foo E, Ross JJ, Jones WT, Reid JB. Plant hormones in arbuscular mycorrhizal symbioses: an emerging role for gibberellins. Ann Bot. 2013;111:769-79.

38. Guinel FC. Ethylene: a hormone at the center-stage of nodulation. Front Plant Sci. 2015;6:1121.

39. Reid D, Liu H, Kelly S, Kawaharada Y, Mun T, Andersen SU, et al. Dynamics of ethylene production in response to compatible nod factor. Plant Physiol. 2018;176:1764-72.

40. D'Haeze W, De Rycke R, Mathis R, Goormachtig S, Pagnotta S, Verplancke C, et al. Reactive oxygen species and ethylene play a positive role in lateral root base nodulation of a semiaquatic legume. Proc Natl Acad Sci. 2003;100: 11789-94.

41. Larrainzar E, Riely BK, Kim SC, Carrasquilla-Garcia N, Yu H-J, Hwang H-J, et al. Deep sequencing of the Medicago truncatula root transcriptome reveals a massive and early interaction between nod factor and ethylene signals. Plant Physiol. 2015;169:233-65.

42. Vela Morales G, Molinero-Rosales N, Ocampo JM, García Garrido JM. Endocellulase activity is associated with arbuscular mycorrhizal spread in pea symbiotic mutants but not with its ethylene content in root. Soil Biol Biochem. 2007;39:786-92.

43. Papadopoulou K, Roussis A, Katinakis P. Phaseolus ENOD40 is involved in symbiotic and non-symbiotic organogenetic processes: expression during nodule and lateral root development. Plant Mol Biol. 1996;30:403-17.

44. Schauser L, Roussis A, Stiller J, Stougaard J. A plant regulator controlling development of symbiotic root nodules. Nature. 1999;402:191-5.

45. Oldroyd GED. Speak, friend, and enter: signalling systems that promote beneficial symbiotic associations in plants. Nat Rev Microbiol. 2013;11:25263. https://doi.org/10.1038/nrmicro2990.

46. Lanfranco L, Bonfante $\mathrm{P}$, Genre A. The mutualistic interaction between plants and Arbuscular Mycorrhizal Fungi. Microbiol Spectr. 2016;4(6). https:// doi.org/10.1128/microbiolspec.FUNK-0012-2016.

47. Tsukagoshi H, Busch W, Benfey PN. Transcriptional regulation of ROS controls transition from proliferation to differentiation in the root. Cell. 2010; 143:606-16. https://doi.org/10.1016/j.cell.2010.10.020.

48. Foreman J, Demidchik V, Bothwell JHF, Mylona P, Miedema H, Torres MA, et al. Reactive oxygen species produced by NADPH oxidase regulate plant cell growth. Nature. 2003:422:442-6.

49. Kwak JM, Mori IC, Pei Z, Leonhardt N, Torres MA, Dangl JL, et al. NADPH oxidase AtrbohD and AtrbohF genes function in ROS-dependent ABA signaling in Arabidopsis. EMBO J. 2003;22:2623-33.
50. Kiirika LM, Schmitz U, Colditz F. The alternative Medicago truncatula defense proteome of ROS - defective transgenic roots during early microbial infection. Front Plant Sci. 2014;5:Article:341.

51. Andrio E, Marino D, Marmeys A, de Segonzac MD, Damiani I, Genre A, et al. Hydrogen peroxide-regulated genes in the Medicago truncatula Sinorhizobium meliloti symbiosis. New Phytol. 2013;198:190-202.

52. Agarwal P, Reddy MP, Chikara J. WRKY: its structure, evolutionary relationship, DNA-binding selectivity, role in stress tolerance and development of plants. Mol Biol Rep. 2011;38:3883-96.

53. Mittler R, Vanderauwera S, Gollery M, Van Breusegem F. Reactive oxygen gene network of plants. Trends Plant Sci. 2004;9:490-8.

54. Santos R, Hérouart D, Sigaud S, Touati D, Puppo A. Oxidative burst in alfalfaSinorhizobium meliloti symbiotic interaction. Mol Plant-Microbe Interact. 2001;14:86-9.

55. Yu H, Xiao A, Dong R, Fan Y, Zhang X, Liu C, et al. Suppression of innate immunity mediated by the CDPK-Rboh complex is required for rhizobial colonization in Medicago truncatula nodules. New Phytol. 2018;220:425-34.

56. Ramu SK, Peng H, Cook DR. Nod factor induction of reactive oxygen species production is correlated with expression of the early Nodulin gene rip1 in Medicago truncatula. Mol Plant-Microbe Interact. 2002;15:522-8.

57. Shaw SL, Long SR. Nod factor inhibition of reactive oxygen efflux in a host legume. Plant Physiol. 2003;132:2196-204. https://doi.org/10.1104/pp.103. 021113.Grant

58. Chen D, Liu C, Roy S, Cousins D, Stacey N, Murray JD. Identification of a core set of rhizobial infection genes using data from single cell-types. Front Plant Sci. 2015;6:Article:575.

59. Cook D, Dreyer D, Bonnet D, Howell M, Nony E, VandenBosch K. Transient Induction of a peroxidase gene in Medicago truncatula precedes Infection by rhizobium meliloti. Plant Cell. 1995;7:43-55.

60. Den Herder J, Lievens S, Rombauts S, Holsters M, Goormachtig S. A symbiotic plant peroxidase involved in bacterial invasion of the tropical legume Sesbania rostrata. Plant Physiol. 2007;144:717-27.

61. Passardi F, Cosio C, Penel C, Dunand C. Peroxidases have more functions than a Swiss army knife. Plant Cell Rep. 2005;24:255-65.

62. Nishikawa A, Ihara Y, Hatakeyamag M, Kangawa K, Taniguchisi N. Purification, CDNA cloning, and expression of UDP-N-acetylglucosamine: BD-mannoside B-1,4N-Acetylglucosaminyltransferase III from rat kidney. J Biol Chem. 1992:267:18199-204.

63. Narasimhan S. Control of glycoprotein synthesis. UDP-GlcNAc:glycopeptide B4-N-acetylglucosaminyltransferase III, an enzyme in hen oviduct which adds GlcNAc in B1-4 linkage to the B-linked mannose of the trimannosyl core of N-glycosyl oligosaccharides. J Biol Chem. 1982;257:10235-42.

64. Sagi M, Davydov O, Orazova S, Yesbergenova Z, Ophir R, Stratmann JW, et al. Plant respiratory burst oxidase homologs impinge on wound responsiveness and development in Lycopersicon esculentum. Plant Cell. 2004;16:616-28. https://doi.org/10.1105/tpc.019398.

65. Nadzieja M, Kelly S, Stougaard J, Reid D. Epidermal auxin biosynthesis facilitates rhizobial infection in Lotus japonicus. Plant J. 2018;95:101-11.

66. Breakspear A, Liu C, Roy S, Stacey N, Rogers C, Trick M, et al. The root hair "Infectome" of Medicago truncatula uncovers changes in cell cycle genes and reveals a requirement for Auxin signaling in Rhizobial infection. Plant Cell. 2014;26:4680-701

67. Gianinazzi-Pearson V, Dumas-Gaudot E, Gollotte A, Tahiri-Alaoui A Gianinazzi S. Cellular and molecular defence-related root responses to invasion by arbuscular mycorrhizal fungi. New Phytol. 1996;133:45-57.

68. Jentschel K, Thiel D, Rehn F, Ludwig-Müller J. Arbuscular mycorrhiza enhances auxin levels and alters auxin biosynthesis in Tropaeolum majus during early stages of colonization. Physiol Plant. 2007;129:320-33.

69. Campanella JJ, Smith SM, Leibu D, Wexler S, Ludwig-Müller J. The auxin conjugate hydrolase family of Medicago truncatula and their expression during the interaction with two symbionts. J Plant Growth Regul. 2008;27: 26-38.

70. Hanlon MT, Coenen C. Rapid report genetic evidence for auxin involvement in arbuscular mycorrhiza initiation. New Phytol. 2011;189:701-9.

71. Hohnjec N, Vieweg MF, Pühler A, Becker A, Küster H. Overlaps in the transcriptional profiles of Medicago truncatula roots inoculated with two different Glomus Fungi provide insights into the genetic program activated during Arbuscular Mycorrhiza. Plant Physiol. 2005;137:1283-301.

72. Güimil S, Chang H, Zhu T, Sesma A, Osbourn A, Roux C, et al. Comparative transcriptomics of rice reveals an ancient pattern of response to microbial colonization. PNAS. 2005;102:8066-70. 
73. Vangelisti A, Natali L, Bernardi R, Sbrana C, Hassani-pak K, Hughes D, et al. Transcriptome changes induced by arbuscular mycorrhizal fungi in sunflower ( Helianthus annuus L.) roots. Sci Rep. 2018;8:1-14. https://doi.org/ 10.1038/s41598-017-18445-0.

74. Arthikala M-K, Montiel J, Sánchez-López R, Nava N, Cárdenas L, Quinto C. Respiratory burst oxidase homolog gene $\mathrm{a}$ is crucial for rhizobium infection and nodule maturation and function in common bean. Front Plant Sci. 2017;8:2003. https://doi.org/10.3389/fpls.2017.02003.

75. Ferguson BJ, Mathesius U. Phytohormone regulation of legume-rhizobia interactions. J Chem Ecol. 2014;40:770-90.

76. Reid D, Nadzieja M, Novák O, Heckmann AB, Sandal N, Stougaard J. Cytokinin biosynthesis promotes cortical cell responses during nodule development. Plant Physiol. 2017;175:361-75.

77. Reid DE, Heckmann AB, Kelly S, Stougaard J. CYTOKININ OXIDASE / DEHYDROGENASE3 maintains Cytokinin homeostasis during root and nodule development in Lotus japonicus. Plant Physiol. 2016;170:1060-74.

78. Hansen M, Chae HS, Kieber JJ. Regulation of ACS protein stability by cytokinin and brassinosteroid. Plant J. 2009;57:606-14.

79. Miyata K, Kawaguchi M, Nakagawa T. Two distinct EIN2 genes cooperatively regulate ethylene signaling in Lotus japonicus. Plant Cell Physiol. 2013;54: 1469-77.

80. Van Zeijl A, RHM ODC, Deinum EE, Charnikhova T, Franssen H, HJM ODC, et al. Rhizobium Lipo-chitooligosaccharide signaling triggers accumulation of Cytokinins in Medicago truncatula roots. Mol Plant. 2015;8:1213-26.

81. Lopez-Gomez M, Sandal N, Stougaard J, Boller T. Interplay of flg22induced defence responses and nodulation in Lotus japonicus. J Exp Bot. 2012;63:393-401.

82. Broughton WJ, Dilworth MJ. Control of leghaemoglobin synthesis in snake beans. Biochem J. 1971;125:1075-80. https://doi.org/10.1042/bj1251075.

83. Smith SE, Smith FA, Jakobsen I. Mycorrhizal Fungi can dominate phosphate supply to plants irrespective of growth responses. Plant Physiol. 2003;133: 16-20. https://doi.org/10.1104/pp.103.024380.

84. Kashofer K, Viertler C, Pichler M, Zatloukal K. Quality control of RNA preservation and extraction from paraffin-embedded tissue: implications for RT-PCR and microarray analysis. PLoS One. 2013;8:e70714.

85. Islas-Flores T, Guillén G, Alvarado-Affantranger X, Lara-Flores M, Sánchez F, Villanueva MA. PvRACK1 loss-of-function impairs cell expansion and morphogenesis in Phaseolus vulgaris L. Root Nodules. Mol Plant-Microbe Interact. 2011;24:819-26. https://doi.org/10.1094/MPMI-11-10-0261.

86. Li H, Durbin R. Fast and accurate long-read alignment with burrowswheeler transform. Bioinformatics. 2010;26:589-95.

87. Anders S, Pyl PT, Huber W. HTSeq-a Python framework to work with highthroughput sequencing data. Bioinformatics. 2015;31:166-9.

88. Anders S, Huber W. Differential expression analysis for sequence count data. Genome Biol. 2010;11:R106.

89. Robinson MD, McCarthy DJ, Smyth GK. edgeR: a bioconductor package for differential expression analysis of digital gene expression data. Bioinformatics. 2010;26:139-40.

90. Jiménez-jacinto V, Sanchez-flores A, Vega-alvarado L. Integrative differential expression analysis for multiple experiments (IDEAMEX): a web server tool for integrated rna-seq data analysis. Front Genet. 2019;10:279.

91. Götz S, García-Gómez JM, Terol J, Williams TD, Nagaraj SH, Nueda MJ, et al. High-throughput functional annotation and data mining with the Blast2GO suite. Nucleic Acids Res. 2008;36:3420-35.

92. Kanehisa M. The KEGG database. Novartis Found Symp. 2002;247:91-103.

\section{Publisher's Note}

Springer Nature remains neutral with regard to jurisdictional claims in published maps and institutional affiliations.

Ready to submit your research? Choose BMC and benefit from:

- fast, convenient online submission

- thorough peer review by experienced researchers in your field

- rapid publication on acceptance

- support for research data, including large and complex data types

- gold Open Access which fosters wider collaboration and increased citations

- maximum visibility for your research: over $100 \mathrm{M}$ website views per year

At $\mathrm{BMC}$, research is always in progress.

Learn more biomedcentral.com/submissions 